\title{
Development of Anti-Cancer Stem Cells as Theranostic Agents in the Treatment of Different Cancer Types: An Update
}

\author{
Arif Malik ${ }^{1^{*}}$, Rabia Rasool ${ }^{1}$, Saima Rubab Khan ${ }^{1}$, Sulayman Waquar ${ }^{1}$, Javed Iqbal ${ }^{2}$, Syed Saeed Ul- Hassan ${ }^{2}$, Mahmood Husain Qazi ${ }^{3}$ and Aamer Qazi $^{3}$ \\ ${ }^{1}$ Institute of Molecular Biology and Biotechnology (IMBB), The University of Lahore, Pakistan \\ ${ }^{2}$ Faculty of Pharmacy, The University of Lahore, Pakistan \\ ${ }^{3}$ Centre for Research in Molecular Medicine (CRiMM), The University of Lahore, Pakistan
}

"Corresponding author: Arif Malik, Institute of Molecular Biology and Biotechnology (IMBB), The University of Lahore, Pakistan, Tel: +03218448196; E-mail: arifuaf@yahoo.com

Received date: April 10, 2017; Accepted date: April 18, 2017; Published date: April 24, 2017

Copyright: (c 2017 Malik A, et al. This is an open-access article distributed under the terms of the Creative Commons Attribution License, which permits unrestricted use, distribution, and reproduction in any medium, provided the original author and source are credited.

\begin{abstract}
Various unprecedented anti-tumor potential targets that robustly target cancer cells while sparing normal cells have been produced by biomedical research in cancer therapeutic intervention for interrupting disease progression and their cure. Stem cells characterize an accessible cell source for novel cell based clinical therapies by inhibiting tumor progression signalling pathways. They carry distinctive characteristics of isolation and migration to tissue inflammation site, inherited modifiability and protein expression. Stem cells are also used in immune-reconstitution and tissue regeneration. Implication of different types of stem cells as an attractive candidate for targeted delivery of anti-neoplastic agents has emerged as a promising field in anticancer therapy. Mutual interaction between cancer cells and stem cells results in effective and safer clinical therapy for tumors. Keeping in view, this review highlights the potential role of stem cells in the progression of tumor metastasis and also summarizes the role of different signaling pathways in carcinogenesis and their involvement in disease treatment. It also focuses on the current advances in stem cells practice in therapeutics of cancer.
\end{abstract}

Keywords: Metastasis; Stem cells; Cancer therapy

\section{Introduction}

The Cancer word is originated from the word "Kapkivos" to depict tumor while the tumor is derived from Latin word to describe tumefaction and swelling [1]. Cancer also termed as malignant neoplasm, has described as a fraction of diseases in which there is uncontrolled growth of cells and invading of tumors in different tissues and organs. This abnormal cell growth can cause mutation in various signaling pathways involved in cell growth, function and division by the activation of pro-oncogenes to oncogenes and suppression of anticancer genes. Cancer cells also become resistant to programmed cell death (apoptosis). Various external and internal factors including immune surveillance, EMT (epithelial-mesenchymal transition), mesenchymal-epithelial transition, angiogenetic switch, genetic and other diseases contribute to the development of early tumors [2]. Cancer is a saga of diseases whose cell versatility and adaptability makes it cure intricate. Various cancers developed inside the body make their detection and treatment extremely difficult such as liver cancer, intestinal cancer and colon cancer while some cancers reside near to the surface like melanoma or retinoblastoma. In general, cancer is referring with fast growing characteristics, but in some cases it is exceedingly slow such as follicular lymphoma [3]. Normal human cells are confined to a specific area from where they belong to while cancerous cells disregard this rule and invade throughout different body organs. This process of invasion is termed as metastasis, which is involved in the destruction of organic/origin where it is developed and spread to organs via the lymphatic system or blood circulation. In cancer patients, it is the most frequent root of mortality. The process of metastasis in carcinomas is well thought to involve discrete steps. The foremost steps are invasion which require loss of cell adhesion of neoplastic epithelial cells and become motile to invade the contiguous tissues. The second step involves intravasation in which the cancerous cells enter the systemic circulation via lymphatic vessels or blood vessel endothelium. Few circulating tumor cells emerge to be capable to endure through the passage of circulation to enter the next step. This step known as extravasation includes few survivor tumor cells that extravagate through endothelium of capillaries to distant sites where they proliferate. Lastly, in these distant sites, even small subsets of metastasis cells are proficient of thriving into malignant secondary tumors [4-6]. Very small percentage of tumor cells belong to primary tumors that can cross circulation and forms distant metastatic abrasion. Almost $90 \%$ cancer cells released from primary tumor can cross one or more of three steps of the metastatic process while only $2 \%$ are able to become micro metastatic, out of which only $0.2 \%$ are capable of inducing angiogenesis and form distant metastatic lesions [7]. Our immune system is quite efficient to recognize and destroy foreign invaders such as viruses, bacteria and abnormal or unfamiliar cells in the body with the help of white blood cells.

Cancerous cells are capable to slip through immune system without activating the immune cells to destroy them in all places either at the initial tumor site or in circulation, at the site of constitution of secondary tumors after metastasis [8]. Even though early diagnosis along with early intervention is the superlative approach to fight cancer, over the existing chemotherapeutic course of therapy, an improved modality is manifestly requisite for the treatment of cancer. Current chemotherapeutic approaches are deficient in the level of selectivity that is required to distinguish between normal body cells and tumor cells which escort mortal side effects. A noteworthy proportion of cancer casualties include death due to atrocious effects of chemotherapy [3]. Cancer is next to cardiovascular and infectious 
diseases in causing death. It accounts approximately 8.2 million deaths every year. It contributes to $12 \%$ in overall human mortalities. The $80 \%$ of cancer is caused by environmental and lifestyle risk factors while remaining 20\% predispose to genetic factors [9]. Main lifestyle risk factors involve the progression of cancer, it includes tobacco and alcohol misuse, stress and poor dietary habits, environmental factors such as bacterial and viral infections contribute geographically in the progression of cancer. It accounts $10 \%$ of all malignancies in developed countries, $25 \%$ in tropical countries. The most frequent viruses put in causing cancer in the cervix; skin, stomach and lymphatic system are Human Papilloma virus, Epstein-Barr virus and human herpes virus or Kaposi sarcoma associated virus which either promotes proliferation of cancer cells or enhancing resistance to programmed cell death result in increasing the survival chances of neoplastic cells [10]. Bacteria and parasites type infectious agents have been proposed to raise the risk of stomach cancer. Additionally, carcinogenic risk factors allow the abnormal cells to resist apoptosis; there is the acquirement of infinite ability of proliferation permitting the progression of tumors of cancerous cells [11].

In normal, healthy tissues, there exists a balance between proliferation of cells and apoptosis. The imbalance between this processes which promote proliferation along with the reduction in cell death can cause cancer. The genetic information which involves DNA replication and entirely and appropriately transmitted to the descendant cells is crucial for the healthy proliferation of cells. However, this DNA information can be disrupted by various external factors such as chemical or radiation, or intrinsic factors which include the addition of inappropriate base pairs by DNA polymerase in the replication process [1]. Cells have a repair mechanism in general that is capable of correcting minor faults in genetic information. But enduring and enormous change in DNA is referred as mutation. These mutations can trigger apoptosis process that is biologically reasonable to prevent brutal DNA damage in healthy cells. Each cell accrues more and more mutations in its DNA over time, which affects different DNA sections that regulate growth and division and develop cancer. The cancerous cells divulge special properties that they are able to evade apoptosis, infinite replication potential, avoid immune destruction and deregulate their cellular energy. Cancer cells can be characterized by inducing persistent angiogenesis, tissue invasion, and metastasis and genome instability. Cancer cells are also different in appearance from normal cells in shape of cell and irregular structures [12]. Tumors are classified as benign or malignant. Benign tumors are confined to the tissues where they proliferate while malignant tumor initially grow only inside a specific tissue and later on extra mutations can generate daughter tumors that shift to other organs invading metastases [13].

\section{Stem Cells}

Stem cells are defined as unspecified cells that are capable of selfrenewal and can differentiate into one or more type of specialized cells. They may vary in differentiation capacity and can be classified depending on the grade of flexibility into totipotent, pluripotent, multipotent and unipotent. With differentiation, their potential to differentiate becomes more confined. Totipotent stem cells are the most versatile among all types. The fertilized egg up till blastomeres stage can be regarded as totipotent and can differentiate and create an entire organism including extra embryonic tissues. Inner cell mass derived embryonic stem cells give rise to embryo itself $[14,15]$. Embryonic stem cells are considered as pluripotent because of their ability to form all the three germ cell layers that are ectoderm, mesoderm and endoderm but they cannot produce extra embryonic tissues unlike totipotent stem cells. Multipotents have even more restrict differentiation potential as compared to pluripotent stem cells, and they are capable of forming various cell types within particular lineages.

Multipotents stem cells include hematopoietic stem cells, which are involved in the formation of red blood cells, white blood cells and platelets. Lastly, unipotent also known as progenitor cells are restricted to differentiate into only one type of cells. Examples include erythroid progenitor cells [16,17]. Somatic or adult stem cells are multipotent stem cells that are found in all tissues to replenish dying cells or the cells that have lost their function throughout the life of a person. Adult stem cells are found in all different tissue types of different organs (muscles, bone marrow, adipose tissues, liver, retina, pancreas, brain, dental pulp, intestines, blood and skin). It was thought earlier that somatic cells are limited in their potential to differentiate and can form only one type of cell restricted in their origin tissue while in the past few decades, studies on stem cells reported that adult stem cells from different tissues are capable of forming cell types from all three germ layers $[17,18]$. These reports unwrap new innovation and endow with an easily reachable cell source that could be used to treat various degenerative diseases.

\section{Cancer Stem Cells and Metastatic Cancer Stem Cells}

Some specific neoplastic cells occupy the properties similar to normal stem cells in having the ability to form all cell types in a specific tumor sample, membrane transport and DNA repair, regulate selfrenewal and differentiate by a variety of external stimuli, oncogenic mutations and show radioresistence and chemoresistence or tumor relapse known as cancer stem cells also called tumor initiating cells (TIC). Cancer stem cells proposed to be a fundamental driving force for the progression of tumor, initiating invasion, metastasis and recurrence [19]. Cancer stems can be formed from various cell sources, including normal adipose derived stromal cells (ASCs), progenitor cells or even differentiated cells [20]. Normal stem cells having an active self-renewal pathway when vulnerable to mutants can be transformed into cancer stem cells while other differentiated or progenitor cells may have to attain more additional mutations particularly in genes associated with self-renewal properties to form cancer stem cells. The CSCs also have the ability to deregulate many signaling pathways, including Wnt, Notch, and Hedgehog pathways. There are assumptions that normal stem cells when form cancer stem cells show more aggressive behavior as compared to cancer stem cells arise from progenitor cells [21]. When cancer research planned to be conducted, the tumor is established in experimental species by injecting tumor cells. Due to high tumorigenic capacity, CSCs are able to form efficient tumor even in limited small concentrations. The ratio of CSCs in acute myeloid leukemia (AML) is as low as 1:10,000. The cancer stem cells were firstly identified in human AML demonstrating that a few neoplastic cells due to their self-renewal and differentiation potential capacity are involved the re-occurrence of the entire disease after several transplantations were found in the immature CD34+CD38- [22].

After this discovery, more researches on solid tumors reported the presence of cancer stem cells in different tumors, including breast, lung, pancreas, brain, colon, prostate, ovarian, melanoma and gastric cancers [23-31]. This CSCs identification opens new aspects in the field of cancer. It is hypothesized that cancer stem cells targeting propose imperative and innovative advances in targeting cancer. Cancer stem 
cell obliteration which is the root of cancer is supposed to show a potential approach to cure cancer or improve cancer survival. Many approaches such as molecular targeted therapy, target molecular signaling pathways, natural compounds and their potential to attack cancer stem cells, usage of stem cell therapy and differentiation therapy are developed to destroy cancer stem cells [32]. Cancer SCs are different from normal stem cells in that they express a unique repertoire of surface biomarkers including CD molecules (CD133. CD44, CD24, CD166), ATP binding cassette Transporters (ABCB5, ABCG2), CXCR4, LRCs, EpCAM, ALDH1, Telomerse and SP cells [33-35]. Cancer stem cells are capable of promoting angiogenesis and lymphangiogenesis [36-40]. Recent studies have linked epithelialmesenchymal transition (EMT) with cancer stem cells [41].

EMT is an essential procedure induced by many pleiotropic transcription factors, including hepatocyte growth factors, Snail, EGF, TGF- $\beta$, Slug, deltaEF1, Zeb1 and Bmi-1, Notch or Hedgehog signaling pathway that disrupt epithelial junction and adhesion which endow the cancer cells to leave the original tumor site and migrate to microenvironment and enter the circulatory system. [42-51]. The concept of metastatic cancer stem cells was foremost introduced in a study conducted in human colorectal cancer [52]. The Wnt $/ \beta$-catenin signaling pathway heterogeneous activation in both solid tumor and metastatic tumor suggesting two different forms of cancer stem (stationary CSCs and Mobile CSCs) in tumor development.

The stationary cancer stem cells are present in epithelial cells and maintain in differentiated regions throughout the progression of tumor but cannot disseminate. However, mobile cancer stem cells are highly capable of being motile leading to rapidly invasive growth and dissemination of tumor cells.

Mobile CSCs function in three parts. One part of mobile CSCs asymmetrically divides, proliferate and differentiate into daughter cells at the site of origin, while another part migrate to some distance away and divide to increase the primary tumor area. The remaining part metastasized to generate tumor in distant locations [52]. Later Andreas Trump et al. [53] proposed metastasis initiating cell model, suggesting that metastatic initiating cells can be differentiated from clones of CSCs by their ability of metastasis in vivo and its expansion in a secondary location necessitate "metastatic niche".

Emerging evidences supports the contribution of cancer stem cells in metastasis by demonstration of heterogeneity of CSCs in colon cancer model in animals which proposed three types of distinct cancer stem cells, including extensively self-renewing long term tumor initiating cells (LT-TICs), tumor transient amplifying cells (T-TACs) and delayed contributing tumor initiating cells (DC-TICs) [54].

Overlapping molecules profiles and signaling pathways regulating both cancer stem cells and cancer metastasis also support this involvement. In orthotopic models, Breast cancer cells in primary tumors and lung metastasis contained an enriched quantity of cancer stem cells that have the ability to form tumors at origin site and also associated with generation of lung metastasis [55].

Invasive cancer stem cells (ICSCs), metastatic associated cancer stem cells in primary tumoriogenesis, are capable of invading extracellular matrix and eventually get access to blood vessels. ICSCs are converted to disseminating cancer cells via deregulation of mutations and modified signaling activation. Only a few of these cells are transformed to metastatic cancer stem cells that can undergo the process of extravasation and generate colonies in faraway organs. They are also induced by various mesenchymal factors or cross talk among cancer stem cells and their surrounding microenvironment [56].

Infiltration of tumor cells informs stromal cells to aid in selfrenewing of cancer stem cells and formation of metastasis is indicated in a recent study [57]. Tumor-derived secreted factors and bone marrow- derived cells promoted pre-metastatic niche derived from the primary tumor in secondary organs provide aid in generating microenvironment for recruitment and colonization of metastatic cancer stem cells [58-61].

Detection of metastatic cancer stem cells in early stages of tumor development provides a valuable method for the prediction and diagnosis of distant metastasis. Bone marrow disseminating cancer cells and circulating tumor cell in the peripheral circulation of tumor patients can be identified and evaluated at single cell level that have highly relevant for metastasis [62,63]. Foremost approaches for disseminating tumor cells detection is antibodies-immunological assay against particular surface marker and PCR assay [62] followed by further experimentation to observe cancer stem cells phenotypes and assessment of tumor generation and metastatic abilities.

The hypothesis of metastatic cancer stem cells has primary inference for metastatic treatments. Metastatic therapy approaches include targeting MCSCs through their particular surface markers (CD133, CD44) [64,65], targeting self-renewal and differentiation pathways [66], metastatic niche disruption and the dormant state by targeting homeostatic processes such as inflammation, hypoxia, epithelialmesenchymal transition and angiogenesis to eradicate metastatic cancer stem cells and diminish recurrence of cancer and metastasis [67].

\section{Renewal and Differentiation Signaling Pathways Involved the Progression of Tumor}

According to researches and explained in the Figure 1, the dogmatic mechanism of cancer stem cells, they rely greatly on the stability of signaling pathways in order to sustain the renewal and differentiation ability of tumor cells. So, their better understanding of these mechanisms aid in discovery and advancement of cancer stem cells targeting anticancer drugs. Disruption and excessive activation of these signaling pathways contribute to tumoriogencity.

Signal pathways such as Wnt, Notch and Hedgehog pathways play a significant part in CSCs reappearance and maintenance. However, there are limited evidences for the dependence of cancer stem cell on these pathways, the development of selective cancer stem cell therapies is necessary to avoid potential side effects that are caused by inhibition of normal stem cell function. Secreted signaling protein, Wnt, is involved in the interaction of receptor molecules with the target cell surface. 


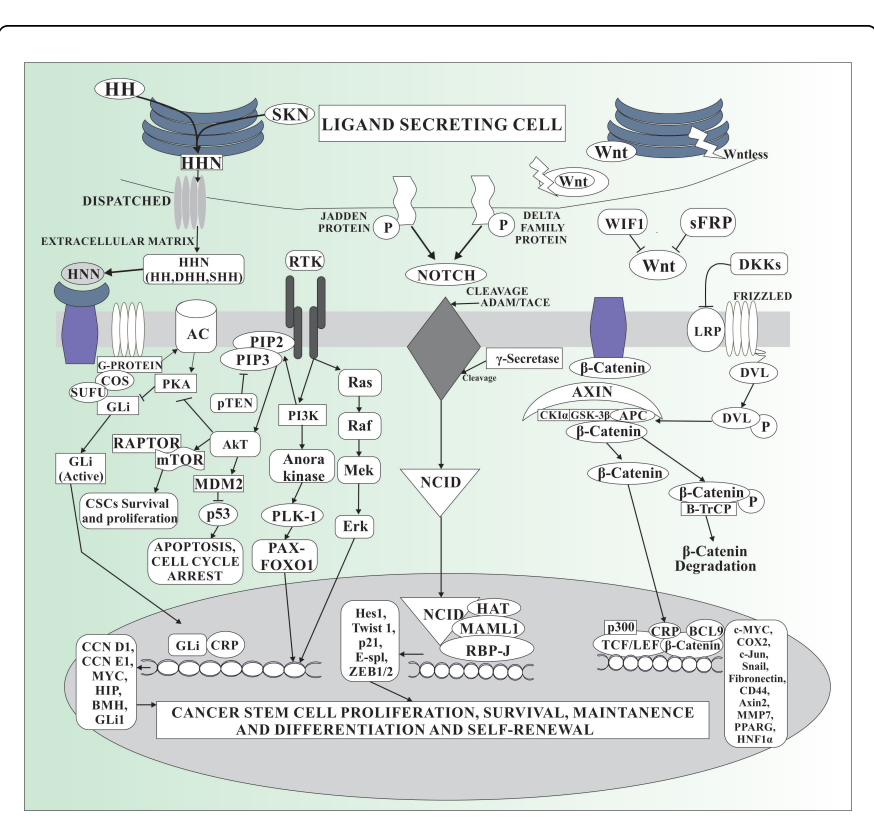

Figure 1: The Wnt, Hedgehog, Notch, pTEN regulator signaling pathways implicating cancer stem cells proliferation and survival. Abbreviations: ADAM(a disinegrin and metalloproteinases), APC (adenomatous polyposis coli protein),CK1 (casein kinase),RBPJ (recombination signal binding protain for immunoglobulin Jregion), Dvl (disheveled), GSK-3B (glycogen synthase kinase-3B), HH (Hedgehog), JAG (Jagged proteins), LRP (low density lipoprotein-related protein), mTOR (mammalian target of rapamycin), NICD (notch intracellular domain), PI3K (phosphatidylinositol 3-kinase), PIP2 (phosphatidylinositol $(3,4)$ bis-phosphate), PIP3 (phosphatidylinositol $(3,4,5)$-tris-phosphate), Ptch (patched proteins), pTEN (phosphatase and tensin homolog protein, BAD (BCL-2 associated agonist of cell death), CCND (cyclin D), Smo (smoothened), WIF1 (Wnt inhibitor factor-1), sFRP (soluble frizzled-related proteins), DKK (dickkopf), E-spl (Enhancer of split), SHH (Sonic hedgehog), IHH (Indian hedgehog).

Myeloid leukemia has reported the significance of Wnt signaling in cancer stem cell biology. It is also implicated in cancer stem cell maintenance in melanoma, colon cancer, breast cancer, and liver cancer and lung tumors. Wnt signaling mediated by $\beta$-catenin depending on its cellular localization is involved in two distinct cell functions. Epithelial adhesion protein E-Cadherin sequestered membrane localized $\beta$-catenin to manage cell to cell adhesion, while $\beta$ catenin cytoplasmic accumulation followed by its nuclear translocation trigger the activation of Wnt targeting genes includes c-Jun, fibronectin, $\mathrm{c}-\mathrm{Myc}$ and cyclin D1. Wnt/ $\beta$-catenin signaling pathways are distinctive feature of epithelial cancer and also significant for metastatic process and EMT (epithelial-mesenchymal transition) [68]. Wnt signaling activation can be associated with stemness is not surprise because EMT enduring tumor cells share characteristics with embryonic stem cells [69]. Few research on mouse model have reported the necessity of $\beta$-catenin in chronic myeloid leukemia for the self-renewal process of both normal hematopoietic stem cells as well as cancer stem cells and activation of $\beta$-catenin transform myeloid precursors in acute myeloid leukemia HoxA9/Meis1 transducer model [70].
Loss of APC induces aberrant response of Wnt/ $\beta$-catenin pathway can be disrupted by small molecule that would therapeutically be efficient agents against colorectal and other cancer. A wide range of compounds that appears beneficial in particularly modulating Wnt $/ \beta$ catenin signals aid in eradicating drug resistant cancer stem cells involved in tumor relapse and metastasis. NSAID by blocking the Wnt targeted COX-2 or by promoting TCF degradation directly involved in disrupting Wnt signaling [71]. Vitamin A, vitamin D and their derivatives like natural compounds compete with $\beta$-catenin/TCF interactions and aid the relocation of $\beta$-catenin to the membrane by $\mathrm{E}$ cadherin. Some recently discovered $\mathrm{Wnt} / \beta$-catenin signaling inhibitors i.e. monoclonal antibodies, WIFI and SFRPs, small interfering RNAs against Wnt1/2, PRI-724 and CWP232291 have become a part of preclinical trials. To achieve this goal additionally the critical regulators of Axin and $\beta$-catenin levels, Tankyrase enzymes can be drugged. The success of this drug is primarily dependent on development TCF/ $\beta$ catenin interaction inhibitors. Wnt signaling is antagonized by XAV939 compound through stimulating the degradation of $\beta$-catenin and axin stabilization [72]. Notch signaling is a highly conserved pathway play a critical role in cell-fate decision, tissue pattern and morphogenicity [73]. Human consist of four Notch receptors that contain a trans-membrane peptide and an extracellular peptide having EGF receptor like repeats. Out of four, Notch 1 and 2 are frequently distributed in all cells, however, only vascular smooth muscles and endothelial cells express Notch 3 and Notch 4. Jagged or delta like family of membrane proteins via binding through ligands cleavage the receptor by members of protease families ADAM and $\gamma$-secretase. This pathway is involved in the maintenance of stem cell in various cancers. Notch signaling activation trigger various factors that transmit bidirectional signals to cancer cells, which in turn expresses both ligand and the receptor. It also conveys signals all over among cancer, stroma and endothelial cells [74]. A study related to Notch signaling in glioblastoma showed inhibition of Notch via endothelial cell intermediate can able to reduce cancerous stem cells in glioblastoma [75]. Notch disruption promotes enhanced radiation response by diminishing CD133+ in glioblastoma. It can be achieved at different stages such as inhibition of $\gamma$-secretase mediated notch cleavage, target Notch ligands or Notch receptor activation and modulation of Notch signal by another pathway components. For examples, Notch 1 induced by PI3K/Akt pathway in the development of melanoma and human arterial endothelial cells. Notch 1 and Notch 2 may be down regulated by a negative regulator GSK $3 \alpha / \beta$.

As a critical mediator of segmental patterning, the Hedgehog signaling pathway was first recognized in fly, Drosophila during embryonic development. It controls proliferation, migration, isolation of target cells in spatial, sequential and concentration reliant manner [76-79]. The signaling pathway is triggered by binding of any of three ligands including sonic (SHh), Desert and Indian Hedgehog to 12-pass transmembrane spanning receptor Patched (Ptch 1). Hedgehog signaling involved in regulating cancer stem cells is evident from many studies conducted on various cancers, including glioblastoma, breast cancer, myeloma, pancreatic adenocarcinoma and chronic myeloid leukemia. An experimental study on chronic myeloid leukemia showed that Hh signaling inhibition by gene disruption of Smo may cause hindrance of BCR-ABL expresses leukemic stem cells and enhanced survival $[80,81]$. A research on multiple myeloma suggested Hedgehog signaling can act via multiple signaling modes with the same cancer and can medicate interaction between cancer stem cells, differentiated tumor cells and microenvironment [82]. The Sonic Hh pathway is associated with NF-kB transcription factor signaling. Hedgehog 
signaling plays a significant role in the progression, homeostasis and abnormality [83]. Hedgehog activated by Smo sends signal intracellularly. The cyclopamine discovery and its subsequent activity in hedgehog signaling pathway aid in Hh inhibitor development with drugs containing properties and improve bioactivity [84]. Smo antagonists and Cur-61414, two groups, screened diverse synthetic chemical libraries for hedgehog antagonists encouraged by identification of druggable hedgehog pathway element $[85,86]$. This all paved the way of various Smo antagonists, including Cur-61414, GDC-0449 and BMS-833923 into clinical trials. The small molecule binding domain in Smo demonstrated that its activity is gated by Hhdependent access to a cellular metabolite with either Smo-activating or Smo-inhibitory properties. Mostly Hedgehog antagonists targeting Smo [87]. Thus success in identifying chemicals that target signal transduction pathways would flare up new potentials for monotherapeutic or combined therapeutic choices that may improve current approaches that aimed common mechanism of rapid abnormal cell growth.

\section{Proposition of Cancer Treatment}

Various treatment strategies are applied depending on the type, site, size of tumor, tumor grade and the patient's health. The most frequent cancer therapies include surgery, radiotherapy and chemotherapy while other less common include immune therapy and monoclonal antibody therapy. With the researches going on cancer provide better understanding of the underlying mechanisms of cancer and evolutionary changes undergo in its treatments to enhance the effectiveness and precision and to increase survivability and life quality of patients. Surgery of tumor originates from ancient Egypt era, while radiation therapy is the product of 1899 . Chemotherapeutical and further cancer target therapy are developed in the $20^{\text {th }}$ century. These all treatments are aimed at impairing the rapid growth and division of cells. Cancer stem cells are resistant to radiotherapy and chemotherapy, however the exact reason is not yet known. Some reasons of this resistance are that these therapies demolish the high proliferating cells, whereas the cancer stem cells less often divide than distinguish cancer cells and cancer stem cells undergo genetic mutations which hinder their response to these therapies. Moreover, cancerous cells are more prone to DNA damage repair, as compared to healthy cells [88]. Three possibilities exist for tumors in which CSCs play a role. Firstly, the development of primary tumors, secondly, refractory cancer stems cells, leading to recurrence of tumor and thirdly, metastasis [89]. Indeed, traditional cancer treatments mark rapid growing neoplastic cells portentous that cancer stem cells may endure due to high resistance to drugs and deliberate proliferating rate. All conventional cancer therapies such as surgery, hormonal therapy, anti-angiogenesis therapy and immunotherapy are not efficient in long term outcome because of their toxicity in normal cells as well as failure in targeting cancer stem cells. In current years, certain cancer stem cell biomarker molecules such as CD133, CD44, ABCG2, and ALDH are recognized. Cancer stem cell features also include deviant signaling pathways, including Wnt, Notch and Hedgehog pathway [90]. Abnormal gene expression and signaling pathway influence the cancer therapy response. Either it can be achieved by targeting specific cancer stem cells biomarkers or targeting essential genes or signaling pathways involved in cancer progression with possible therapies targeted against tumor initiating cells. However, due to presence of fusion transcript, the therapy may not be curative [91]. The pathway comparison of stem cell homing and metastasis have proved beneficial to reduce the toxicity of drugs like treatment of mice with cyclopamine, a hedgehog pathway inhibitor that hinders the medulloblastomes growth without any visible toxic effects [92].

\section{Stem Cells Source Involved in Cancer Therapy}

For the therapeutic purposes ESCs would ideally be the actual source of stem cells when compared with ASCs, as ESCs has an indefinite life span and high totipotency whereas; narrow life span and lower totipotency is linked with the ASCs. Although, ESCs use has constraints ethically (Health Department, UK, National Institutes of International Society and Health for the Research of Stem Cell) and there has been imposed a restriction for their use in therapeutic and research purposes [93] and disallowed in various countries round the world. Additionally, in mice the stem cells that have higher totipotency are more tumorogenic [94]. Therefore, for the facility of availability and lowly constrained on the ethical issues, the stem cells that are commonly used for therapeutic and research purposes are ASCs. Another reason for the ASCs use is that they are easily accessible as compared to ESCs. As stated in literature, from bone marrow (MSCs and HSCs), ASCs are the stem cells that are studied most commonly [95]. In bone marrow HSCs has been supported by MSCs and have the capacity to discern both in vitro and in vivo into the various dissimilar mesenchymal cells like cartilage, bone, muscle, fat, marrow stroma and tendon [96].

Pre-implanted human embryos that are 5 days old derive the ESCs, however, it has the potential risk of damaging the embryo. ASCs can be found from various tissues, e.g. synovium, bone, adipose tissue, deciduous teeth, blood vessels, brain, blood of the umbilical cord [97-100]. In the clinical and research fields, there has been a restriction for the use of ESCs due to ethical and legal reasons and for stem cells ASCs turns out to be the main supplement. However, various sites can provide ASCs, but the ideal source has not been found yet. Most commonly, there is an acquirement of ASCs from peripheral blood and bone marrow. To get ASCs, a very common procedure is the aspiration of bone marrow (BM), but it has an association with the morbidity in the sort of sepsis and wound infection complication [101]. ASCs are obtainable from the adipose tissues, e.g. infraptellar fat and abdominal fat $[102,103]$ that is eventually less morbid and less invasive procedure than the aspiration of bone. It has been described that there is no visible difference in the aging of cells, growth kinetics, and transduction of stromal cells that are adhered and yield from the stem cells that are obtained from adipose tissues or bone marrow [104]. An easily accessible and safe route is also provided by the peripheral blood for the isolation of ASCs with reduced morbidity. Through the peripheral blood the ASCs use has exhibited to bring on more NK (Natural Killer) and T cells as compared with the ASCs of bone marrow [105]. Recently, there is a claim to obtain stem cells from amniotic fluid, not including any harm to the embryo and mother.

Peripheral blood or bone marrow is the most common source of the stem cells. The bone marrow aspiration procedure is invasive and it is associated with possible complications that are potential and includes fracture, infection of wounds, and the sepsis, whereas the procedure for the isolation of PBSCs is invasive with lesser extent and eventually less morbid. Higher NK cell and CD4 T cells have been induced by the PBSCs as compared to the stem cells that are obtained from bone marrow [105]. Hence, the stem cells that are obtained from the peripheral blood are considered and are the preferred source of stem cells, nonetheless many clinical; trials have been publicized many conclusions about the controversial nature comparing with the PBSCs and $\mathrm{BM}$ stem cells. It has also been noticed that there is a variation 
with PBSCs in the occurrence of the graft versus the reaction of the host as compared with to the BM-stem cells [106,107]. Storek et al. suggested that the subset counts of higher lymphocyte are yielded by PBSC [108] while Hernandez et al. noticed that there is no difference in the lymphocyte number, but he noted a faster re-constitution of the cytotoxic subsets [109]. Similarly, controversial results were presented by these trials that include host disease versus graft, disease free survival, overall survival and immune recovery. There has been documented a double stem cell transplantation to improve the overall survival when compared to the single stem cell transplantation [110]. G-CSF (Granulocyte-colony stimulating factor) aids in the rapid growth and differentiation of the progenitor cells that are haematopoietic. Also, G-CSF have been reported to mobilize the stem cells of autologous peripheral blood to save and grow in size the telomerase length [111]. There are many agents that enhance the activity of G-CSF in the stem cell mobilization. These are docetaxel and paclitaxel [112,113], lithium [114], recombinant methionyl human stem cell factor (r-metHuSCF) [115] and recombinant human thrombopoietin [113].

In the use of the stem cells, the limiting factor of major value in the clinical area is the stem cell life span. Theoretically, from this point of view the embryonic stem cells are the best due to their life span that is indefinite replicative and is linked to their expression of telomerase [116]. Although, practically, in the clinical area the embryonic stem cell use is much restricted. Many ASCs do not have adequate activity of telomerase and thus the loss of the telomerase cannot be prevented. At every division, there has been seen a shortening of telomerase and the replication process slows down and in the end, the cells eventually cease to divide (phase of crisis) [117]. Hence, we might not be able to get enough stem cells of adult for performing the clinical task. One solution is the genetic manipulation to extend the span of replication of stem cells by the gene introduction that is involved in controlling replicative life span. In humans, by overcoming the replicative aging, this can be achieved by the use of ectopic expression of the telomerase gene hTERT [118]. In the recent years, various studies suggested that the hTERT expressing the stem cells, it continues to increase rapidly and maintain their differentiation ability [119-122]. Similarly, there has been an immortalization of hMSCs by transduction with the HPV16 E6/E7 in vitro with not having any changes of neoplastic nature [123]. If it turns out to be successful to connote this principle in the clinical practice, stem cells of quantitative amount may not be the prognostic factor in future outcomes.

\section{Stem Cell-Based Therapies for Cancer Treatment}

A number of therapies related to stem-cell rising as a talented approach to deal with cancer. Different types of stem cell displayed inherent tropism of tumors. The purpose is to find out the anticancerous agents that vigorously attack malignant cells without having any damaging effects on healthy normal cells. Negative aspects of these conservative treatments lead to extensive damage of normal tissues. Various mature stem-cells illustrate inherent tumor tropic properties; they are too smart for the release of anticancer agents. A dual policy runs in which stem cells distribute cancer cells to micro metastatic lesions that causes precise release at proper place. Stem cells can be adapted or they can discharge anticancer agents, thus avoiding the short half-lives that various chemotherapeutic agents display. The production of preclinical stem cell therapies leftover, translating into clinic necessitates that become more technical and rigid. Stem cells propose medicine due to the regeneration and therapeutic prospective, a great deal to investigate them. Without proper information the clinical purpose of stem cells can be put at risk, stated by Stamina Foundation, Italy [124]. It is required to remove expectations from publicity to differentiate the therapeutic potential that stem cells convey clinically from the overstated promises that pass through the media and scientific text. This point of view needs to emphasize the current improvement in stem cells related treatment. At first it is important to focus on the status of technologies that have been used to control and originate stem cells in clinical studies to attack malignant cells.

\section{Stem Cells as Therapeutical Delivery Tools}

To enhance the efficacy of anticancer agents, it is required to avoid the related problems like adverse pharmacokinetics and other problems in the development of constant concentrations in surrounding areas of tumor. If talking about tumor formation in the brain, there are various compounds that are unable to pass through blood-brain barrier, this is another confusing aspect. Stem cells are used as rescue agents and they deal with all these provocations. By the use of any other probable rescue technique or process, it has, the more authorized comeback than any other be considered as a conservative rescue process. The restorative action of SC treatment makes as best when SCs evade the host immune system regarding the point of malignant. Though these features are much more attractive and these characteristics remain to some degree. It is very well known that SCs have immunosuppressive properties due to the assets of cytokines and growth factors which adapt the cellular and innate immune pathways of host [125-127].

Numerous researches have established that transplantation of different mature and initiated allogeneic donor SCs trigger an immune response; however, they become have negative response [128-132]. For instance, fibroblasts are allogeneic mesenchymal SCs, they give the impression to be fewer immunogenic as compared to allogeneic nonstem cell donor cells [133]. In xenografts mouse models, the wandering ability of neural stem cells and neural originators were exposed at first because of having the skill to reside within the skull in brain tumors and non-neural tumors in other areas of body [134-136]. Furthermore, neural SCs not only consolidate into the primary tumor surroundings and also move in the direction of the intracranial micro-satellite that characterizes malignant tumors of brain e.g., glioblastoma [134]. A various types of human SCs have tumor-tropic characteristics [137-139]. In tumor-tropism of SCs cellular and molecular procedures are complicated. A variety of chemokine-chemokine receptors are related to tumor tropism and may be the most excellent considered is stromal cell derived factor 1 (SDF1; also called as CXCL12) and the receptor is chemokines receptor 4 (CXCR4). In the passage of various stem cells and matrix metalloproteinase 1 (MMP 1), proteinaseactivated receptor 1 (PAR 1) classes involving mature stem cells [140-143], embryonic stem cells (ESCs) [144] and induced pluripotent stem cells (iPSCs), the SDF1-CXCR4 signaling axis have been exposed to have the most important function [145]. Some essential pathways have been expelled by adding $\mathrm{P} 13 \mathrm{~K}$ signaling, urokinase-type plasminogen activator (uPA)-uPA receptor (uPAR), MMP1proteinase-activated receptor 1 (PAR1) and vascular endothelial growth factor receptor 2 (VEGFR2) [146-150]. The quantity of SCs travel to the tumor is affected by different characters involving the environment of SCs and the microenvironment of tumor. To gain knowledge about the characters that affect the wandering potential of 
SCs will permit the better capacity to adapt SC immigration and enhance the therapeutic ability of SCs.

\section{Development of Anticancer Stem Cells}

Unaltered stem cells can have inherent anti-tumor properties to factors that are released by stem cells and physical relationship and connections that are recognized among the stem cells and tumor cells [151-153]. Stem cells have been established in many different ways to cover up cancer and several are in detail as given below. Therapeutic proteins release stem cells and they can be grouped into two wide portions that consist of whether they perform in a straight way on cells or may be on underneath supporting tumor cells, blood vessels and stroma are the examples. The adaptation of SCs by viral transduction to show the transgenes encoding releasable effector proteins, though non-viral methods have shown various benefits, like low host immunogenicity [154,155]. Pro-apoptotic protein tumor necrosis factor- related apoptosis-inducing ligand (TRAIL) are the factors that affect directly and attached to death receptor 4 (DR4; this is also called as TRAILR1 and DR5 also called as TRAILR2), these are known for causing apoptosis [156,157]. Proteins can struggle to block the attachment of endogenous ligands to associated receptor is the different policy that has consequences in the removal of proliferation pathways in the cancer and related cells.

An example the appearance of organic agents that attach to epidermal growth factor receptor (EGFR) or with tumor specific variant EGFRvIII $[158,159]$ and cytokines like interferon- $\beta$ (IFN $\beta$ ) and IFNa41, it controls the tumor growth in a negative way but in different preclinical cancer models [160-164]. Some of the effectors involving that agents restrain the development of tumor-associated vasculature, for instance antangiogenic thrombospondin 1 (TSP also called as THBS1) [165] and PEX which is a part of MMP2, successfully restrict the development of tumor accumulation due to having a nonpermissive microenvironment [166]. The underlying principle is that the immunosuppressive cancer location can be changed into one that makes the immune action, not in favour of cancer [167]. Some of the human MSCs have made for the release of IL-12 or IL-18 and they have been experienced in mice having carcinoma of renal cell, cervical tumor and glioblastoma [168-172]. All of these researches to cancer and stem cells inter-related continued company of ILs released by SC along with transfers in immune profile, involving high concentrations of IFN $\gamma$, establishment of natural, healthy killer cells and employment of tumor-specific $\mathrm{T}$ cells, thus leads to prolonged existence and the estimation of proceeds.

\section{Induction of Cancer Cell Death via Genetic Modification of Stem Cells}

Stem cells are manufactured to show enzyme that converts nontoxic pro-drugs in to a cytotoxic drug that can destroy neighboring cells by naked results, this is a policy which is described by SC mediated suicide gene therapy. The advantage of SC-mediated suicide therapy is that the SC is destroyed after its therapeutic consequences. Three of the latest suicide gene systems are used. There is the conversion of 5-fluorocytosine into the toxic antimetabolite 5fluorouracil by the action of cytosine deaminase (CD). Thymidine kinase (HSV-Tk) is the herpes simplex virus which converts ganciclovir (GCV) into GCV-monophosphate, in the next step phophorylation occurs which converts it into GCV-triphosphate, which stops DNA formation. Carboxylesterase (CE) enzyme has a role in the conversion of pro-drug irinotecan to topoisomerase inhibitor SN-38. In the adaptation of MSCs and NSCs, CD-5-FC system has been used and this system is good for the practice in mouse models for the treatment of brain tumors, for example glioblastoma and medulloblastoma, that consequent on the failure of tumor mass and continued existence [173-177]. The HSV-Tk system which depends upon the development of gap junctions in between the SC and target cells found nearby for competent results that have shown efficiency in various various animal models of cancer, which includes glioblastoma, breast cancer and prostate [178-180]. Human neural stem cells harnessing the CE-irinotecan system have resulted to be most efficient in preclinical models of ovarian and lung cancer, also medulloblastoma [181-183].

\section{Nanoparticles Carrier Function of Stem Cells}

The nanoparticle release mechanism is capable to have high levels of insoluble chemotherapeutic reagents, whereas defending them from damage by the insensitive atmosphere. Moreover, the outside of nanoparticles can be adapted to change the properties for example stability, solubility and targeting. Though, this technology offers significant release by the use of nanoparticles in vivo that has been demanding to the competent approval, ineffective distribution in solid tumors and unable to attack the micro metastatic lesions [184]. To defeat these barriers, the use of SCs as nanoparticles release agents that can travel to develop malignancies and to set down the overloaded nanoparticles that are related to the cancer $[185,186]$.

Though, the "Trojan horse" law is conceptually clear-cut, its completion needs more technical thoughts as well as developing well organized resources to weigh down SCs without disturbing their essential properties and calculating the release of nanoparticles from the SC to make sure the constant and under attack treatment. Come with the story is to weight the cell membrane of MSCs with porous silica nano-rattles having doxorubicin. These weighed MSCs were exposed to travel towards and encourage apoptosis in intracranial tumors; they are more competent than injection of doxorubicin only [187]. Different methods apply to the passive and calveolin or clathrin related nanoparticles into SCs [186]. At the existence of tumor, nanoparticles are secreted from stem cells, moreover, in the consequence of membrane damage due to cytolic gathering, or causing death by the use of outdoor factor like photo-induction or causing hyperthermia [188-190]. Nanoparticle related a treatment with SC release is a company that alters more examination for cancer treatment.

\section{Oncolytic Virus Loaded Stem Cells}

Cancer oncolytic virotherapy is a novel therapeutic choice where the capability of a virus to endorse cell lysis is exploited and reprogrammed for selective demolishing cancerous cells. Such treatment modalities demonstrated anti-neoplastic activity in preclinical and clinical settings and emerge as well acceptable when experienced in clinical assessment. Though, the clinical triumph of oncolytic virotherapy has been considerably hindered due to their inability to aimed systematic metastasis, which is in part due to the therapeutic virus inability to survive in the patient circulation to target tumors at distant sites [191]. Many experimented oncolytic viruses therapeutic efficacy have been restricted in clinical trials because of various physiological, immunological and intramural barriers $[192,193]$. An early study established that oncolytic virus infected cell infection can protect the therapeutic payload from the host immune 
system and work as factories for the production of virus and boost the therapeutic efficacy of oncolytic virus. Although an array of cell lineage has the potential as cell carriers, abundant researches have established to prove stem cells as an incredibly attractive cell carrier system in oncolytic viral-therapy. The ideal cell carrier's desire to be vulnerable to viral infectivity as well as sustain viral infection, uphold immunosuppressive properties to protect the loaded viruses from the host immune system and most prominently acquire an intrinsic tumor homing ability to deliver loaded viruses directly to metastatic site [191].

Their efficiency against quiescent and drug transporteroverexpressing cells, able them to elude the cancer stem cells typical mechanism used to resist radiotherapies and chemotherapy. The use of oncolytic virus in neoplastic therapy is based on observation of tumor regression in the face of natural viral infection [194]. Oncolytic adenovirus, ONYX-015 and H101 has been experimented in random trials. Virus can play the role of immunomodulators and cancer vaccines either by unlocking tumor antigen or by activating the immune response against infection. In addition, oncolytic viruses are capable of targeting some particular characteristics of cancer stem cells, including cell surface proteins, cancer stem cell microenvironment and transcription factors [195]. Oncolytic viruses include herpes simplex virus-1, reovirus, adenovirus, vaccinia virus, myxoma virus, etc. have shown their activity in eliminating cancer stem cells.

\section{Enhancement in Stem Cells Efficacy}

Diverse approaches that are applied to increase the stem cells therapeutically potential have categorized on the bases of their amplified intrinsic stem cells properties, augmenting their delivery or function in combination with secreted factors to raise their anti-cancer effectiveness. The in vivo survival of stem cells till the entire complete elimination of cancer and proper migration to the malignancies is important to maximize the SC-based therapy outcome. Much work is done in endeavoring to increase these characteristics. Allogeneic stem cells have somehow been immune-evasive, but their use in immunecompetent recipients are still abandoned [133]. Genetic manipulation of stem cells is abundance of non-genetic approaches depend on the surface binding or loading of stem cells intracellularly with effector moieties. These are either immunosuppressive directly or that modify stem cells behavior that adopts immunosuppressive qualities.

Human mesenchymal stem cells can be loaded with chemical containing microparticles that give specific cellular characteristics of the targeted cells, including secretion rate, differentiation potential and proliferative properties. Surrounding cells may be affected through paracirne mechanism unlock up the opportunity of driving whole stem cells towards preferred immune-suppressive phenotypes [196,197]. Various ways can be applied to raise the antitumor potential of stem cells, in which one is augmenting the existing transductory signaling pathways. For example, up-regulated expression of receptor of chemokines in stem cells can significantly increase chemokines mediated migration towards intracranial gliomas [198,199]. Moreover, local irradiating cancers directed by inflammation in damaged tissues can enhance stem cell tropism [200,201]. The clinical allegation of which includes the treatment of solid tumors by radiotherapy. The stem cells tumor targeted response in trail by radiotherapy may be improved as a suitable side effect.

\section{Implication of Combination of Therapies for Enhancing Stem Cell Efficiency}

Heterogeneous inhabitants of cells that are genetically or epigenetically unstable are constituents of cancer [202]. Moreover, the resistance against chemotherapeutic developed in the cancer cells, and it happens intrinsically or even during the phase of evolution (acquired resistance), hence making it difficult for the disease to get eliminated from the body using a single drug treatment [203]. Malignancies can be treated better by using the treatment of combination method. A single approach can be made to certain SCs which at the same time also express and also excrete unlike agents used as therapeutics' having multi cancerous pathways as their targets as their therapeutic goal. While it is theoretically perplexing to make a suitable choice for tumor-definite targets and ensuing the SC management, there are numbers of studies which supports the study of using certain bimodal SCs and SC which have than one molecule functioning. Combining of HSV-tk treatment with TRAIL in glioblastoma models is the best examples of bimodal SCs, breast cancer models in mice and CD with IFN $\beta$ in glioblastoma $[160,178,204]$. The combination of the proapoptotic TRAIL protein with an EGFR-specific nano-body is due to a bi-functional protein which provides its therapeutic goals using multiple anti-tumor sites (ENb; a small antibody fragment) that create a conjugate known as the immune-conjugate (ENb-TRAIL) that alongside inhibit tumor growth and stimulate apoptosis [158]. Tumor burden can be decreased by the transport of ENb-TRAIL from the NSCs expressively and enhances the endurance in mice of extremely malignant glioblastoma. A parallel approach was made and was used by commencing the umbilical cord of human MSCs that excretes a CD20 definite single chained Fv fragment of antibody that is fused to a TRAIL (scFvCD20-TRAIL). In a mouse model of non-Hodgkin's lymphoma the delivery of the MSCs of scFvCD20-TRAIL was far more effective as compared to the MSC transfer of TRAIL unaccompanied due to the parallel inhibition of proliferation and encouraged apoptosis precisely in tumor cells [205].

Many studies have shown the result to improve the result of SC using a single therapy must be combined with an additional agent which is used to work in co-operation with the SC therapy or alerts another population that is resistant to the secreted biological agent. Example is the uses of different class of drug which have shown to work in collaboration with SC-transferred TRAIL that increased the mode of action of p53-dependent protein. This may include certain inhibitors that are proteasome in nature, such as bortezomib, genotoxic drugs such as cisplatin, HDAC inhibitors, the PI3K-mTOR inhibitor PI-103, MicroRNA inhibitors and short hairpin RNA (shRNA) $[156,206]$. The molecular mechanisms that motivate an enhancement of response to a whole class of stimuli in addition to the one that is repeated to TRAIL is multifaceted and it is reliant on the mode of action of each agent. Nonetheless, death receptors up regulation, a protein that inhibits apoptosis and activating p53-dependent apoptosis can all donate to this mixture effect. Another conducted study shows that by merging an acid known as valproic acid with human bone marrow resultant MSCs that expresses HSV-tk improves the outcome through enhancing the gap junction proteins conexin 43 expressions and it is also known as the gap junction $\alpha 1$ and also the gap junction protein connexin 26 which is also known as the gap junction $\beta 2$, hence consenting the enhancement of diffusion of GCV monophosphate in the cell culture. This theory was explained in the living species; those mice, which were managed with GCV and valproic acid show a significant positive result in surviving for longer duration as compared 
to those mice which were managed only with GCV [179]. In clinics, for the initiation for imposing the SC treatment the clinics must be standardized according to the health care. Surgical interventions may be applied to those patients who have developed glioblastomas tailed by the ionization from different radiation and also temozolomide. Kim et al. [207] conducted a study and shown that TRAIL expressed from MSCs were more beneficial in the management of glioblastomas in the existence of temozolomide. Another study showing that glioblastoma model was applied by a NSc which carries an oncolytic in combination with radiation and temozolomide. In mice having glioblastoma xenografts, this combination shown to improve the survival rate. Fascinatingly, instead of applying NSc prior to as compared to after the chemotherapy and temozolomide treatment, mice survival rate were increased to about 30\% [208]. Towards radiotherapy, these results attribute to the effects of oncolytics virus over glioblastomas model, and it presents the significance of experimenting SC treatment within the current standard of care for any certain type of tumor.

\section{Encapsulation of Stem Cells}

For the therapeutic SC in vivo, route of administration has a deep effect over the anti-tumor and the survival rate. Example is in the case of brain tumors in which the intra nasal route of SC is now becoming a novel route of administrations [209,210]. In cancer bearing mice another strategy is introduced to encapsulate the SC in vivo studies. Decomposable hydrogels, materials of synthetic extracellular matrix ECM which are composed of hyuloric acid, agarose, alginate and many other polymers permit the encapsulation of cells into the biocompanionable and semi-permeable scaffolds [211]. When coming to their ability in providing better effectiveness in the vivo cells and providing a suitable physiological environment for the cell survival and also helps against different immune responses, in various rats model recyclable hydrogels have been utilized for the SC encapsulating [212-214].

Reagan et al. [215] conducted a study and shown the significance of encapsulating MSCs that were formed for the expression of TRAIL in porous and bio-attuned silk scaffolds. Primary breast tumor growths were noticed to get reduced by the MSCs encapsulated and those who were expressing TRAIL and also shows significant results in bone, liver and lungs metastases of mice models. MSCs that were Matrigelencapsulated were modified to express IL-12 shows positive anti-tumor effects when it was compared with MSCs non-encapsulated which is expressing IL-12 in mouse models of melanoma when they are administrated intra-tumorally [169]. The major disorders are the vascular dysfunction and also the blood-brain barrier in any tumor environment that is responsible for the impairment of the efficient transport of different therapeutic molecules in brain tumor, while encapsulation of SC is an important viewpoint for connecting tumorspecific agents. For the treatment of gliastomas we have engineered a new form of approach by encapsulating SC gliastomas removal of that specific part of the body using xenograft in different mice models that can summarize the clinical situation of surgical removal of tumor bulk as much as it can of a glioblastoma [216]. Mouse and human MSCs and NSCs encapsulation in synthetic Extra Cellular Matrix show positive enhancement in retention of surgical removal of cavity and allow the selective migration of the tumor outside the gel. Moreover, when the synthetic ExtraCellular Matrix encapsulated SCs expresses an apoptotic TRAIL protein, or get infected with oHSV TRAIL and were placed in the glioblastoma tumor removed part of the body it shows significant rise in the survival rate of those mice, which were being experiential as compared to those whose removed body part were inserted with a non-therapeutic encapsulate SCs [216]. Mutually, in pre-clinical scenarios, these studies show the use of these encapsulated SC and it also provides a podium for treating the cancer patients with surgical removal of that cancerous part.

\section{Stem Cell Efficacy and Fate}

Once for treating the patient with SC encapsulated therapies the clinicians should have a necessary knowledge about the efficacy, fate and the survival rate of this therapeutic approach. In vivo, several imaging techniques can be used to image SC therapy. SC therapy characteristics were imaged and asses by the occipital techniques when they were inserted in small animal cancer models. Those stem cells, which are modified for expressing the fluorescents and the bioluminescent stably reported the construction can be pictured by using the intra-vital fluorescence microscopy and the dual bioluminescence. Tumors when labeled correspondingly, the process of tumor formation, visualization is possible, migration of SC and also the tumor killing process. At cellular level the histological analysis allows the SC to localize, hence making it a powerful approach for management $[159,216]$. Moving to humans or any other larger animal, Due to tissue penetration the use of optical visualization is limited, increasing the needs of the usage of non-invasive imaging techniques. However, only in the mouse models the usage of these techniques is being applied. Example is the detection of SC is using the magnetic resonance imaging (MRI) that has been overloaded with superparamagnetic particles for determining tumor tropism and therapeutic impact [217-220]. Detection of ferumoxytol through MRI regarded as human NSCs established their feasibility, safety, usefulness in mice, and it also donated to the US Food and Drug Administration (FDA) permitting the examination of this method in human Phase clinical trial. To measure the SC fate and systemic distribution Positron emission tomography (PET) has been applied [221]. Fascinatingly, HSV-tk in combination with numerous radioactive substrates can be used as a standard for imaging, PET, and at high resolution SCs which is expressing this specific gene can be visualized [222]. Likewise, new imaging techniques are being introduced as well as new agents are engineered, in vivo the ability to record the SC behavior is increased. Hence the result is in the improvement in biological understanding, and that is in the near future the scope of SC based therapies in clinical scenarios can be improved.

\section{Doorway of Therapeutic Stem Cells in Clinical Trials}

Regardless the use of SCs in clinical trial as therapeutic uses in a very large scale and diversity, the uses of these therapeutic agents in clinical scenarios is very rare in current state. Now days in the present data regarding therapeutic trial, gliablasstoma treatment is in the major ratio among other treatments, hence showing that this disease has a poor prognosis and the need of original approaches regarding its management is needed. In short duration from now for active immunity against tumor will be introduced by modifying the use of MSCs and NSCs whose aim is the establishment of the safety and efficacy of MSCs that expresses IL-12 (GX-051) and the route of administration of these drugs are intra-tumorally in patients suffering from head and neck cancer. Garcia-Castro and their co-workers demonstrated that using auto-logous MSCs laden with oncolytic adenovirus (ICOVIR-5) in a sample of four children shows efficacy and safety with metastatic neuroblastoma in several doses via infusion administration [223]. A single case was documented about the 
reduction of disease in a child after three years of therapy. In a recurrent glioblastoma, modified SCs that modified CD are being tested and it is followed by the surgical removal of the cancerous mass, than the patients are treated by injecting the anti-tumor Pro-drug 5-FC after the modified SCs are introduced into the removed portion of the body. While this trial is continuing, there are two more trials which support the theory that whether combining leucovorin calcium with SCs that modifies CD OR irinotecan hydrochloride to additionally alert glioblastoma cells. These trials are not, however appealing and are not able to engage the patients and also the results are also waiting from the prior trials which were conducted for the safety and efficacy of these trials which were explored.

\section{Conclusion}

This review primarily focuses on the cancer stem cells in metastasis and potential involvement of stem cells in cancer therapy. Apart from involvement of cancer stem cells in the initiation, propagation and invasion of metastasis, they are also concerned to therapeutic resistance. In vivo, multifunctional tools based on stem cells for targeted tumor delivery is based on the tropic properties and multifunctionalization of stem cells and serve as promising alternative therapeutic approach for the treatment of an array of malignancies and disorders. This may focus the requirement of further work in gene differentiation, carcinogenetic signaling pathways and identification of various new molecular biomarkers for the development of innovative therapies aimed to hamper regeneration of cancer stem cells and cancer relapse. The current cancer stem cells conception has intended scientific community towards a diverse broad research field area and possible potential for further therapeutic modalities for cancer treatment.

\section{Acknowledgements}

The authors are highly thankful to Prof. Dr. M. H. Qazi, Center for Research in Molecular Medicine (CRiMM) to provide the innovative and financial support for the project.

\section{Conflict of Interest}

The authors declare no conflict of interest.

\section{References}

1. Wikipedia: Cancer.

2. Hillen T, Enderling H, Hahnfeldt P (2013) The tumor growth paradox and immune system-mediated selection for cancer stem cells. Bulletin of Mathematical Biology 75: 161184.

3. Priya P, Reyes VM (2015) A Cancer Biotherapy Resource. arXiv preprint arXiv: 1602.08111.

4. Fidler IJ (2003) The pathogenesis of cancer metastasis: the 'seed and soil' hypothesis revisited. Nat Rev Cancer 3: 453-458.

5. Nguyen DX, Bos PD, Massagué J (2009) Metastasis: from dissemination to organ-specific colonization. Nat Rev Cancer 9: 274-284.

6. Valastyan S, Weinberg RA (2011) Tumor metastasis: molecular insights and evolving paradigms. Cell 147: 275-292.

7. Luzzi KJ, MacDonald IC, Schmidt EE, Kerkvliet N, Morris VL, et al. (1998) Chambers AF and Groom AC. Mul $\neg$ tistep nature of metastatic inefficiency: dor $\urcorner$ mancy of solitary cells after successful extrav 7 asation and limited survival of early micro-metastases. Am J Patho 153: 865-873.

8. Goldenberg SL, Pickles T, Chi KN (2014) The intelligent patient guide to prostate cancer. BookBaby.
9. WHO (2014) World Cancer Report.

10. De Martel C, Ferlay J, Franceschi S, Vignat J, Bray F, et al. (2012) Global burden of cancers attributable to infections in 2008: a review and synthetic analysis. Lancet Oncol 13: 607-615.

11. Jangamreddy JR. Cancer and cancer stem cell targeting agents: A focus on salinomycin and apoptin (Doctoral dissertation, Linköping University Electronic Press).

12. Sadava D, Heller HC, Orians GH (2008) Purves Biologie. Spektrum Akademischer Verlag.

13. Burger M (2014) An SDE Approach to Cancer Therapy Including Stem Cells (Doctoral dissertation, Informatics Institute).

14. Evans MJ, Kaufman MH (1981) Establishment in culture of pluripotential cells from mouse embryos. Nature 292: 154-156.

15. Thomson JA, Itskovitz-Eldor J, Shapiro SS, Waknitz MA, Swiergiel JJ, et al. (1998) Embryonic stem cell lines derived from human blastocysts. Science 282: 1145-1147.

16. Martinez-Agosto JA, Mikkola HK, Hartenstein V, Banerjee U (2007) The hematopoietic stem cell and its niche: a comparative view. Genes Dev 21: 3044-3060.

17. Serafini M, Verfaillie CM (2006) Pluripotency in adult stem cells: state of the art. Semin Reprod Med 24: 379-388.

18. Keating A (2006) Mesenchymal stromal cells. Curr Opin Hematol 13: 419-425.

19. Moltzahn FR, Volkmer JP, Rottke D, Ackermann R (2008) "Cancer stem cells"-lessons from Hercules to fight the Hydra. Urol Oncol 26: 581-589.

20. Visvader JE, Lindeman GJ (2008) Cancer stem cells in solid tumours: accumulating evidence and unresolved questions. Nat Rev Cancer 8: 755-768.

21. Park CY, Tseng D, Weissman IL (2009) Cancer stem cell-directed therapies: recent data from the laboratory and clinic. Mol Ther 17: 219-230.

22. Lapidot T, Sirard C, Vormoor J, Murdoch B, Hoang T, et al. (1994) A cell initiating human acute myeloid leukaemia after transplantation into SCID mice. Nature 367: 645-648.

23. Al-Hajj M, Wicha MS, Benito-Hernandez A, Morrison SJ, Clarke MF (2003) Prospective identification of tumorigenic breast cancer cells. Proc Natl Acad Sci. 100: 3983-3988.

24. Hemmati HD, Nakano I, Lazareff JA, Masterman-Smith M, Geschwind $\mathrm{DH}$, et al. (2003) Cancerous stem cells can arise from pediatric brain tumors. Proc Natl Acad Sci U S A 100: 15178-15183.

25. O'Brien CA, Pollett A, Gallinger S, Dick JE (2007) A human colon cancer cell capable of initiating tumour growth in immunodeficient mice. Nature 445: 106-110.

26. Fang D, Nguyen TK, Leishear K, Finko R, Kulp AN, et al. (2005) A tumorigenic subpopulation with stem cell properties in melanomas. Cancer Res 65: 9328-9337.

27. Hermann PC, Huber SL, Herrler T, Aicher A, Ellwart JW, et al. (2007) Distinct populations of cancer stem cells determine tumor growth and metastatic activity in human pancreatic cancer. Cell Stem Cell 1: 313-323.

28. Collins AT, Berry PA, Hyde C, Stower MJ, Maitland NJ (2005) Prospective identification of tumorigenic prostate cancer stem cells. Cancer Res. 65: 10946-10951.

29. Bapat SA, Mali AM, Koppikar CB, Kurrey NK (2005) Stem and progenitor-like cells contribute to the aggressive behavior of human epithelial ovarian cancer. Cancer Res 65: 3025-3029.

30. Ho MM, Ng AV, Lam S, Hung JY (2007) Side population in human lung cancer cell lines and tumors is enriched with stem-like cancer cells. Cancer Res 67: 4827-4833.

31. Fukuda K, Saikawa Y, Ohashi M, Kumagai K, Kitajima M, et al. (2009) Tumor initiating potential of side population cells in human gastric cancer. Int J Oncol 34: 1201-1207.

32. Hu Y, Fu L (2012) Targeting cancer stem cells: a new therapy to cure cancer patients. Am J Cancer Res 2: 340-356.

33. Medema JP (2013) Cancer stem cells: the challenges ahead. Nat Cell Biol $15: 338-344$. 
34. Stower H (2012) Telomeres: stem cells, cancer and telomerase linked by WNT. Nat Rev Genet 13: 521.

35. Moserle L, Ghisi M, Amadori A, Indraccolo S (2010) Side population and cancer stem cells: therapeutic implications. Cancer Lett 288: 1-9.

36. Bjerkvig R, Johansson M, Miletic H, Niclou SP (2009) Cancer stem cells and angiogenesis. Semin Cancer Biol 19: 279-284.

37. Ribatti D (2012) Cancer stem cells and tumor angiogenesis. Cancer Lett 321: 13-17.

38. Ping YF, Yao XH, Jiang JY, Zhao LT, Yu SC, et al. (2011) The chemokine CXCL12 and its receptor CXCR4 promote glioma stem cell-mediated VEGF production and tumour angiogenesis via PI3K/AKT signalling. J Pathol 224: 344-354.

39. Ye XZ, Yu SC, Bian XW (2010) Contribution of myาeloid-derived suppressor cells to tumor-in $\neg$ duced immune suppression, angiogenesis, in ᄀvasion and metastasis. J Genet Genomics 37: 423-430.

40. Yao XH, Ping YF, Bian XW (2011) Contribution of cancer stem cells to tumor vasculogenic mimicry. Protein Cell 2: 266-272.

41. Mani SA, Guo W, Liao MJ, Eaton EN, Ayyanan A, et al. (2008) The epithelial-mesen $\neg$ chymal transition generates cells with properties of stem cells. Cell 133: 704-715.

42. Thiery JP, Acloque H, Huang RY, Nieto MA (2009) Epithelialmesenchymal transitions in development and disease. Cell 139: 871-890.

43. Cano A, Perez-Moreno MA, Rodrigo I, Locascio A, Blanco MJ, et al. (2000) The transcription factor snail controls epithelial-mesenchymal transitions by repressing E-cadherin expression. Nat Cell Biol 2: 76-83.

44. Bolos V, Peinado H, Perez-Moreno MA, Fraga MF, Esteller M, et al. (2003) The transcription factor Slug represses E-cadherin expression and induces epithelial to mesenchymal transi-tions: a comparison with Snail and E47 repres $\neg$ sors. J Cell Sci 116: 499-511.

45. Eger A, Aigner K, Sonderegger S, Dampier B, Oehler S, et al. (2005) DeltaEF1 is a transcriptional re $\neg$ pressor of E-cadherin and regulates epithelial plasticity in breast cancer cells. Oncogene 24: 2375-2385.

46. Liu Y, El-Naggar S, Darling DS, Higashi Y, Dean DC (2008) Zeb1 links epithelial-mesenchymal transition and cellular senescence. Development 135: 579-588.

47. Song LB, Li J, Liao WT, Feng Y, Yu CP, et al. (2009) The polycomb group protein Bmi-1 represses the tumor suppressor PTEN and in $\neg$ duces epithelial-mesenchymal transition in hu $\neg$ man nasopharyngeal epithelial cells. J Clin In ᄀvest 119: 3626-3636.

48. Yilmaz M, Christofori G (2009) EMT, the cytoskeleton, and cancer cell invasion. Cancer Metastasis Rev 28: 15-33.

49. Vermeulen L, De Sousa EMF, van der Heijden M, Cameron K, de Jong $\mathrm{JH}$, et al. (2010) Wnt activity defines colon cancer stem cells and is regulated by the microenviᄀronment. Nat Cell Biol 12: 468-476.

50. Moustakas A, Heldin CH (2007) Signaling net-works guiding epithelialmesenchymal transi-tions during embryogenesis and cancer pro $\neg$ gression. Cancer Sci 98: 1512-1520.

51. Polyak K, Weinberg RA (2009) Transitions between epithelial and mesenchymal states: acquisition of malignant and stem cell traits. Nat Rev Cancer 9: 265-273.

52. Brabletz T, Jung A, Spaderna S, Hlubek F, Kirchner T (2005) Opinion: migrating cancer stem cells - an integrated concept of malignant tumour progression. Nat Rev Cancer 5: 744-749.

53. Baccelli I, Trumpp A (2012) The evolving concept of cancer and metastasis stem cells. J Cell Biol 198: 281-293.

54. Dieter SM, Ball CR, Hoffmann CM, Nowrouzi A, Herbst F, et al. (2011) Distinct types of tumor-initiating cells form human colon cancer tu $\neg$ mors and metastases. Cell Stem Cell 9: 357-365.

55. Liu H, Patel MR, Prescher JA, Patsialou A, Qian D, et al. (2010) Cancer stem cells from human breast tumors are in 7 volved in spontaneous metastases in ortho-topic mouse models. Proc Natl Acad Sci U S A 107: 18115-18120.

56. Moriyama T, Ohuchida K, Mizumoto K, Cui L, Ikenaga N, et al. (2010) Enhanced cell migration and invasion of $\mathrm{CD} 133+$ pancre 7 atic cancer cells cocultured with pancreatic stromal cells. Cancer 116: 3357-3368.
57. Malanchi I, Santamaria-Martinez A, Susanto E, Peng H, Lehr HA, et al. (2012) Interactions between cancer stem cells and their niche govern metastatic colonization. Na 7 ture 481: 85-89.

58. Kaplan RN, Riba RD, Zacharoulis S, Bramley AH, Vincent L, et al. (2005) VEGFR1-posi-tive haematopoietic bone marrow progenitors initiate the pre-metastatic niche. Nature 438: 820-827.

59. Sceneay J, Smyth MJ, Möller A (2013) The pre-metastatic niche: finding common ground. Cancer Metastasis Rev 32: 449-464.

60. Kaplan RN, Psaila B, Lyden D (2006) Bone marrow cells in the 'premetastatic niche': within bone and beyond. Cancer Metastasis Rev 25: 521-529.

61. Psaila B, Lyden D (2009) The metastatic niche: adapting the foreign soil. Nat Rev Cancer 9: 285-293.

62. Pantel K, Brakenhoff RH, Brandt B (2008) Detec $\neg$ tion, clinical relevance and specific biological properties of disseminating tumour cells. Nat Rev Cancer 8: 329-340.

63. Pantel K, Alix-Panabières C (2007) The clinical significance of circulating tumor cells. Nat Clin Pract Oncol 4: 62-63.

64. Wu Y, Wu PY (2009) CD133 as a marker for cancer stem cells: progresses and concerns. Stem Cells Dev 18: 1127-1134.

65. Draffin JE, McFarlane S, Hill A, Johnston PG, Waugh DJ (2004) CD44 potentiates the adherาence of metastatic prostate and breast cancer cells to bone marrow endothelial cells. Cancer Res 64: 5702-5711.

66. Takebe N, Harris PJ, Warren RQ, Ivy SP (2011) Tarาgeting cancer stem cells by inhibiting Wnt, Notch, and Hedgehog pathways. Nat Rev Clin Oncol 8: 97-106.

67. Ye J, Wu D, Wu P, Chen Z, Huang J (2014) The cancer stem cell niche: cross talk between cancer stem cells and their microenvironment. Tumour Biol 35: 3945-3951.

68. Zhao C, Blum J, Chen A, Kwon HY, Jung SH, et al. (2007) Loss of betacatenin impairs the renewal of normal and CML stem cells in vivo. Cancer Cell 12: 528- 541.

69. Kalluri R, Weinberg RA (2009) The basics of epithelial-mesenchymal transition. J Clin Invest 119: 1420-1428.

70. Wang Y, Krivtsov AV, Sinha AU, North TE, Goessling W, et al. (2010) The Wnt/beta-catenin pathway is required for the development of leukemia stem cells in AML. Science 327: 1650-1653.

71. Takahashi-Yanaga F, Kahn M (2010) Targeting Wnt Signaling: Can We Safely Eradicate Cancer Stem Cells? Clinical Cancer Research 16: 3153-3162.

72. Huang SM, Mishina YM, Liu S, Cheung A, Stegmeier F, et al. (2009) Tankyrase inhibition stabilizes axin and antagonizes Wnt signalling. Nature 461: 614-620.

73. Yin L, Velazquez OC, Liu ZJ (2010) Notch signaling: emerging molecular targets for cancer therapy. Biochem Pharmacol 80: 690-701.

74. Guo S, Liu M, Gonzalez-Perez RR (2011) Role of Notch and its oncogenic signaling crosstalk in breast cancer. Biochim Biophys Acta 1815: 197-213.

75. Hovinga KE, Shimizu F, Wang R, Panagiotakos G, Van Der Heijden M, et al. (2010) Inhibition of notch signaling in glioblastoma targets cancer stem cells via an endothelial cell intermediate. Stem Cells 28: 1019-1029.

76. Nüsslein-Volhard C, Wieschaus E (1980) Mutations affecting segment number and polarity in Drosophila. Nature 287: 795-801.

77. Lee JJ, von Kessler DP, Parks S, Beachy PA (1992) Secretion and localized transcription suggest a role in positional signaling for products of the segmentation gene hedgehog. Cell 71:33-50.

78. Mohler J, Vani K ( 1992) Molecular organization and embryonic expression of the hedgehog gene involved in cell-cell communication in segmental patterning of Drosophila. Development 115: 957-971.

79. Tabata T, Eaton S, Kornberg TB (1992) The Drosophila hedgehog gene is expressed specifically in posterior compartment cells and is a target of engrailed regulation. Genes Dev 6: 2635-2645.

80. Dierks C, Beigi R, Guo GR, Zirlik K, Stegert MR, et al. (2008) Expansion of Bcr-Abl-positive leukemic stem cells is dependent on Hedgehog pathway activation. Cancer Cell 14: 238-249. 
Citation: Malik A, Rasool R, Khan SR, Waquar S, lqbal J, et al. (2017) Development of Anti-Cancer Stem Cells as Theranostic Agents in the Treatment of Different Cancer Types: An Update. J Carcinog Mutagen 8: 291. doi:10.4172/2157-2518.1000291

Page 12 of 15

81. Zhao C, Chen A, Jamieson CH, Fereshteh M, Abrahamsson A, et al. (2009) Hedgehog signalling is essential for maintenance of cancer stem cells in myeloid leukaemia. Nature 458: 776-779.

82. Peacock CD, Wang Q, Gesell GS, Corcoran-Schwartz IM, Jones E, et al. (2007) Hedgehog signaling maintains a tumor stem cell compartment in multiple myeloma. Proc Natl Acad Sci U S A 104: 4048-4053.

83. Shelton CC, Zhu L, Chau D, Yang L, Wang R, et al. (2009) Modulation of gamma-secretase specificity using small molecule allosteric inhibitors. Proc Natl Acad Sci U S A 106: 20228-20233.

84. Peukert S, Miller-Moslin K (2010) Small-molecule inhibitors of the hedgehog signaling pathway as cancer therapeutics. ChemMedChem 5: 500-512.

85. Chen JK, Taipale J, Cooper MK, Beachy PA (2002) Inhibition of Hedgehog signaling by direct binding of cyclopamine to Smoothened. Genes Dev 16: 2743-2748.

86. Tremblay MR, Lescarbeau A, Grogan MJ, Tan E, Lin G, et al. (2009) Discovery of a potent and orally active hedgehog pathway antagonist (IPI-926). J Med Chem 52: 4400-4418.

87. Sinha S, Chen JK (2006) Purmorphamine activates the Hedgehog pathway by targeting Smoothened. Nat Chem Biol 2: 29-30.

88. Wikipedia: Management of Cancer. Management_of_cancer.

89. Jordan CT, Guzman ML, Noble M (2006) Cancer stem cells. N Engl J Med 355: 1253-1261.

90. Galderisi U, Cipollaro M, Giordano A (2006) Stem cells and brain cancer. Cell Death Differ 13: 5-11.

91. Branford S, Hughes TP, Rudzki Z (1999) Monitoring chronic myeloid leukaemia therapy by real-time quantitative PCR in blood is a reliable alternative to bone marrow cytogenetics. Br J Haematol 107: 587-599.

92. Berman DM, Karhadkar SS, Hallahan AR, Pritchard JI, Eberhart CG, et al. (2002) Medulloblastoma growth inhibition by hedgehog pathway blockade. Science 297: 1559-1561.

93. Thomson JA, Itskovitz-Eldor J, Shapiro SS, Waknitz MA, Swiergiel JJ, et al. (1998) Embryonic stem cell lines derived from human blastocysts. Science 282: 1145-1147

94. Serakinci N, Guldberg P, Burns JS, Abdallah B, Schrodder H, et al. (2004) Adult human mesenchymal stem cell as a target for neoplastic transformation. Oncogene 23: 5095-5098.

95. Sylvester KG, Longaker MT (2004) Stem cells: review and update. Arch Surg 139: 93-99.

96. Simonsen JL, Rosada C, Serakinci N, Justesen J, Stenderup K, et al. (2002) Telomerase expression extends the proliferative life-span and maintains the osteogenic potential of human bone marrow stromal cells. Nat Biotechnol 20: 592-596.

97. Awad HA, Wickham MQ, Leddy HA, Gimble JM, Guilak F (2004) Chondrogenic differentiation of adipose-derived adult stem cells in agarose, alginate, and gelatin scaffolds. Biomaterials 25: 3211-3222.

98. Lee OK, Kuo TK, Chen WM, Lee KD, Hsieh SL, et al. (2004) Isolation of multipotent mesenchymal stem cells from umbilical cord blood. Blood 103: 1669-1675.

99. Miura M, Gronthos S, Zhao M, Lu B, Fisher LW, et al. (2003) SHED: stem cells from human exfoliated deciduous teeth. Proc Natl Acad Sci U S A 100: 5807-5812.

100. Sottile V, Halleux C, Bassilana F, Keller H, Seuwen K (2002) Stem cell characteristics of human trabecular bone-derived cells. Bone 30: 699-704.

101. Pittenger MF, Mackay AM, Beck SC, Jaiswal RK, Douglas R, et al. (1999) Multilineage potential of adult human mesenchymal stem cells. Science 284: 143-147.

102. Dragoo JL, Samimi B, Zhu M, Hame SL, Thomas BJ, et al. (2003) Tissueengineered cartilage and bone using stem cells from human infrapatellar fat pads. J Bone Joint Surg Br 85: 740-747.

103. Huang JI, Zuk PA, Jones NF, Zhu M, Lorenz HP, et al. (2004) Chondrogenic potential of multipotential cells from human adipose tissue. Plast Reconstr Surg 113: 585-594.
104. De Ugarte DA, Morizono K, Elbarbary A, Alfonso Z, Zuk PA, et al. (2003) Comparison of multi-lineage cells from human adipose tissue and bone marrow. Cells Tissues Organs 174: 101-109.

105. Talmadge JE, Reed E, Ino K, Kessinger A, Kuszynski C, et al. (1997) Rapid immunologic reconstitution following transplantation with mobilized peripheral blood stem cells as compared to bone marrow. Bone Marrow Transplant 19: 161-172.

106. Weiss L, Or R, Slavin S, Naparstek E, Reich S, et al. (2004) Immunotherapy of murine leukemia following non-myeloablative conditioning with naive or G-CSF mobilized blood or bone marrow stem cells. Cancer Immunol Immunother 53: 358-362.

107. Couban S, Simpson DR, Barnett MJ, Bredeson C, Hubesch L, et al. (2002) A randomized multicenter comparison of bone marrow and peripheral blood in recipients of matched sibling allogeneic transplants for myeloid malignancies. Blood 100: 1525-1531.

108. Storek J, Dawson MA, Storer B, Stevens-Ayers T, Maloney DG, et al. (2001) Immune reconstitution after allogeneic marrow transplantation compared with blood stem cell transplantation. Blood 97: 3380-3389.

109. Hernandez MD, del Canizo MC, Gonzalez M, Caballero MD, LopezBerges MC, et al. (1998) Immune reconstitution after autologous progenitor hemopoietic cell transplantation. A study comparing autologous bone marrow and autologous peripheral blood transplantation. Med Clin (Barc) 110: 768-773.

110. Attal M, Harousseau JL, Facon T, Guilhot F, Doyen C, et al. (2003) Single versus double autologous stem cell transplantation for multiple myeloma. N Engl J Med 349: 2495-2502.

111. Szyper-Kravitz M, Uziel O, Shapiro H, Radnay J, Katz T, et al. (2003) Granulocyte colony-stimulating factor administration upregulates telomerase activity in CD34+ haematopoietic cells and may prevent telomere attrition after chemotherapy. Br J Haematol 120: 329-336.

112. Danova M, Porta C, Ferrari S, Brugnatelli S, Comolli G, et al. (2000) Cell cycle status and apoptosis of hematopoietic progenitor cells released into the peripheral blood after taxanes and granulocyte colony-stimulating factor in breast cancer patients. Oncol Rep 7: 585-589.

113. Somlo G, Sniecinski I, ter Veer A, Longmate J, Knutson G, et al. (1999) Recombinant human thrombopoietin in combination with granulocyte colony-stimulating factor enhances mobilization of peripheral blood progenitor cells, increases peripheral blood platelet concentration, and accelerates hematopoietic recovery following high-dose chemotherapy. Blood 93: 2798-2806.

114. Canales MA, Arrieta R, Hernandez-Garcia C, Bustos JG, Aguado MJ, et al. (1999) A single apheresis to achieve a high number of peripheral blood CD34+ cells in a lithium-treated patient with acute myeloid leukaemia. Bone Marrow Transplant 23: 305.

115. Prosper F, Sola C, Hornedo J, Arbona C, Menendez P, et al. (2003) Mobilization of peripheral blood progenitor cells with a combination ofcyclophosphamide, r-metHuSCF and filgrastim in patients with breast cancer previously treate $d$ with chemotherapy. Leukemia 17: 437-441.

116. Soltysova A, Altanerova V, Altaner C (2005) Cancer stem cells. Neoplasma 52: 435-440.

117. Hamada H, Kobune M, Nakamura K, Kawano Y, Kato K, et al. (2005) Mesenchymal stem cells (MSC) as therapeutic cytoreagents for gene therapy. Cancer Sci 96: 149-156.

118. Bodnar AG, Ouellette M, Frolkis M, Holt SE, Chiu CP, et al. (1998) Extension of life-span by introduction of telomerase into normal human cells. Science 279: 349-352.

119. Abdallah BM, Haack-Sorensen M, Burns JS, Elsnab B, Jakob F, et al. (2005) Maintenance of differentiation potential of human bone marrow mesenchymal stem cells immortalized by human telomerase reverse transcriptase gene despite [corrected] extensive proliferation. Biochem Biophys Res Commun 326: 527-538.

120. Natesan S (2005) Telomerase extends a helping hand to progenitor cells. Trends Biotechnol 23: 1-3.

121. Roy NS, Nakano T, Keyoung HM, Windrem M, Rashbaum WK, et al. (2004) Telomerase immortalization of neuronally restricted progenitor 
cells derived from the human fetal spinal cord. Nat Biotechnol 22: 297-305.

122. Simonsen JL, Rosada C, Serakinci N, Justesen J, Stenderup K, et al. (2002) Telomerase expression extends the proliferative life-span and maintains the osteogenic potential of human bone marrow stromal cells. Nat Biotechnol 20: 592-596.

123. Hung SC, Yang DM, Chang CF, Lin RJ, Wang JS, et al. (2004) Immortalization without neoplastic transformation of human mesenchymal stem cells by transduction with HPV16 E6/E7 genes. Int J Cancer 110: 313-319.

124. Abbott A (2014) Leaked files slam stem-cell therapy. Nature 505: 139-140.

125. Jones BJ, McTaggart SJ (2008) Immunosuppression by mesenchymal stromal cells: from culture to clinic. Exp Hematol 36: 733-741.

126. Bernardo ME, Fibbe WE (2013) Mesenchymal stromal cells: sensors and switchers of inflammation. Cell Stem Cell 13: 392-402.

127. Milwid JM, Elman JS, Li M, Shen K, Manrai A, et al. (2014) Enriched protein screening of human bone marrow mesenchymal stromal cell secretions reveals MFAP5 and PENK as novel IL-10 modulators. Mol Ther 22: 999-1007.

128. Muraoka KI, Shingo T, Yasuhara T, Kameda M, Yuan W, et al. (2006) The high integration and differentiation potential of autologous neural stem cell transplantation compared with allogeneic transplantation in adult rat hippocampus. Exp Neurol 199: 311-327.

129. Zhao T, Zhang ZN, Rong Z, Xu Y (2011) Immunogenicity of induced pluripotent stem cells. Nature 474: 212-215.

130. Eliopoulos N, Stagg J, Lejeune L, Pommey S, Galipeau, J (2005) Allogeneic marrow stromal cells are immune rejected by MHC class Iand class II-mismatched recipient mice. Blood 106: 4057-4065.

131. Zangi L, Margalit R, Reich-Zeliger S, Bachar-Lustig E, Beilhack A, et al. (2009) Direct imaging of immune rejection and memory induction by allogeneic mesenchymal stromal cells. Stem cells 27: 2865-2874.

132. Schu S, Nosov M, O'Flynn L, Shaw G, Treacy O, et al. (2012) Immunogenicity of allogeneic mesenchymal stem cells. J Cell Mol Med 16: 2094-2103.

133. Ankrum JA, Ong JF, Karp JM (2014) Mesenchymal stem cells: immune evasive, not immune privileged. Nat Biotechnol 32: 252-260.

134. Aboody KS, Brown A, Rainov NG, Bower KA, Liu S, et al. (2000) Neural stem cells display extensive tropism for pathology in adult brain: evidence from intracranial gliomas. Proc. Natl Acad. Sci USA 97: 12846-12851.

135. Brown AB, Yang W, Schmidt NO, Carroll R, Leishear KK, et al. (2003) Intravascular delivery of neural stem cell lines to target intracranial and extracranial tumors of neural and non-neural origin. Human gene therapy 14: 1777-1785.

136. Tang Y, Shah K, Messerli SM, Snyder E, Breakefield X, et al. (2003) In vivo tracking of neural progenitor cell migration to glioblastomas. Hum Gene Ther 14: 1247-1254.

137. Yang J, Lam DH, Goh SS, Lee EX, Zhao Y, et al. (2012) Tumor Tropism of Intravenously Injected Human-Induced Pluripotent Stem Cell-Derived Neural Stem Cells and Their Gene Therapy Application in a Metastatic Breast Cancer Model. Stem cells 30: 1021-1029.

138. Shah K, Bureau E, Kim DE, Yang K, Tang Y, et al. (2005) Glioma therapy and real-time imaging of neural precursor cell migration and tumor regression. Ann Neurol 57: 34-41.

139. Gondi CS, Veeravalli KK, Gorantla B, Dinh DH, Fassett D, et al. (2010) Human umbilical cord blood stem cells show PDGF-D-dependent glioma cell tropism in vitro and in vivo. Neuro Oncol 12: 453-465.

140. Suárez-Álvarez B, López-Vázquez A, López-Larrea C (2012) Mobilization and homing of hematopoietic stem cells. Adv Exp Med Biol 741: 152-170.

141. Shi M, Li J, Liao L, Chen B, Li B, et al. (2007) Regulation of CXCR4 expression in human mesenchymal stem cells by cytokine treatment: role in homing efficiency in NOD/SCID mice. Haematologica 92: 897-904.

142. Wynn RF, Hart CA, Corradi-Perini C, O'Neill L, Evans CA, et al. (2004) A small proportion of mesenchymal stem cells strongly expresses functionally active CXCR4 receptor capable of promoting migration to bone marrow. Blood 104: 2643-2645.
143. Park SA, Ryu CH, Kim SM, Lim JY, Park SI, et al. (2011) CXCR4transfected human umbilical cord blood-derived mesenchymal stem cells exhibit enhanced migratory capacity toward gliomas. International journal of oncology 38(1): 97.

144. Guo Y, Hangoc G, Bian H, Pelus LM, Broxmeyer HE (2005) SDF-1/ CXCL12 enhances survival and chemotaxis of murine embryonic stem cells and production of primitive and definitive hematopoietic progenitor cells. Stem Cells 23: 1324-1332.

145. Koizumi S, Gu C, Amano S, Yamamoto S, Ihara H, et al. (2011) Migration of mouse-induced pluripotent stem cells to glioma-conditioned medium is mediated by tumor-associated specific growth factors. Oncology letters 2: $283-288$.

146. Kendall SE, Najbauer J, Johnston HF, Metz MZ, Li S, et al. (2008) Neural Stem Cell Targeting of Glioma Is Dependent on Phosphoinositide 3Kinase Signaling. Stem cells 26: 1575-1586.

147. Vallabhaneni KC, Tkachuk S, Kiyan Y, Shushakova N, Haller H, et al. (2011) Urokinase receptor mediates mobilization, migration, and differentiation of mesenchymal stem cells. Cardiovasc. Res. 90: 113-121.

148. Gutova M, Najbauer J, Frank RT, Kendall SE, Gevorgyan A, et al. (2008) Urokinase plasminogen activator and urokinase plasminogen activator receptor mediate human stem cell tropism to malignant solid tumors. Stem cells 26: 1406-1413.

149. Schmidt NO, Przylecki W, Yang W, Ziu M, Teng Y, et al. (2005) Brain tumor tropism of transplanted human neural stem cells is induced by vascular endothelial growth factor. Neoplasia 7: 623-630.

150. Ho IA, Chan KY, Ng WH, Guo CM, Hui KM, et al. (2009) Matrix Metalloproteinase 1 Is Necessary for the Migration of Human Bone Marrow-Derived Mesenchymal Stem Cells Toward Human Glioma. Stem Cells 27: 1366-1375.

151. Motaln H, Gruden K, Hren M, Schichor C, Primon M, et al. (2012) Human mesenchymal stem cells exploit the immune response mediating chemokines to impact the phenotype of glioblastoma. Cell Transplant 21: 1529-1545.

152. Schichor C, Albrecht V, Korte B, Buchner A, Riesenberg R, et al. (2012) Mesenchymal stem cells and glioma cells form a structural as well as a functional syncytium in vitro. Exp. Neurol 234: 208-219.

153. Qiao L, Xu Z, Zhao T, Zhao Z, Shi M, et al. (2008) Suppression of tumorigenesis by human mesenchymal stem cells in a hepatoma model. Cell Res 18: 500-507.

154. Hu YL, Huang B, Zhang TY, Miao PH, Tang GP, et al. (2012) Mesenchymal stem cells as a novel carrier for targeted delivery of gene in cancer therapy based on nonviral transfection. Mol. Pharm 9: 2698-2709.

155. Jo J, Hong S, Choi WY, Lee DR (2014) Cell-penetrating peptide (CPP)conjugated proteins is an efficient tool for manipulation of human mesenchymal stromal cells. Sci Rep 4: 4378.

156. Stuckey DW, Shah K (2013) TRAIL on trial: preclinical advances in cancer therapy. Trends Mol Med 19: 685-694.

157. Sasportas LS, Kasmieh R, Wakimoto H, Hingtgen S, Van De Water JA, et al. (2009) Assessment of therapeutic efficacy and fate of engineered human mesenchymal stem cells for cancer therapy. Proc Natl Acad Sci USA 106: 4822-4827.

158. van de Water JA, Bagci-Onder T, Agarwal AS, Wakimoto H, Roovers RC, et al. (2012) Therapeutic stem cells expressing variants of EGFR-specific nanobodies have antitumor effects. Proc Natl Acad Sci USA 109: 16642-16647.

159. Balyasnikova IV, Ferguson SD, Sengupta S, Han Y, Lesniak MS (2010) Mesenchymal stem cells modified with a single-chain antibody against EGFRvIII successfully inhibit the growth of human xenograft malignant glioma. PLoS ONE 5: e9750.

160. Ito S, Natsume A, Shimato S, Ohno M, Kato T, et al. (2010) Human neural stem cells transduced with IFN- $\beta$ and cytosine deaminase genes intensify bystander effect in experimental glioma. Cancer gene therapy 17: 299-306.

161. Studeny M, Marini FC, Champlin RE, Zompetta C, Fidler IJ, et al. (2002) Bone marrow-derived mesenchymal stem cells as vehicles for interferon$ß$ delivery into tumors. Cancer research 62: 3603-3608. 
162. Ren C, Kumar S, Chanda D, Kallman L, Chen J, et al. (2008) Cancer gene therapy using mesenchymal stem cells expressing interferon- $\beta$ in a mouse prostate cancer lung metastasis model. Gene therapy 15: 1446-1453.

163. Dembinski JL, Wilson SM, Spaeth EL, Studeny M, Zompetta C, et al. (2013) Tumor stroma engraftment of gene-modified mesenchymal stem cells as anti-tumor therapy against ovarian cancer. Cytotherapy 15: 20-32.

164. Ren C, Kumar S, Chanda D, Chen J, Mountz JD, et al. (2008) Therapeutic Potential of Mesenchymal Stem Cells Producing Interferon-a in a Mouse Melanoma Lung Metastasis Model. Stem Cells 26: 2332-2338.

165. van Eekelen M, Sasportas LS, Kasmieh R, Yip S, Figueiredo JL, et al. (2010) Human stem cells expressing novel TSP-1 variant have antiangiogenic effect on brain tumors. Oncogene 29: 3185-3195.

166. Kim SK, Cargioli TG, Machluf M, Yang W, Sun Y, et al. (2005) PEXproducing human neural stem cells inhibit tumor growth in a mouse glioma model. Clinical Cancer Research 11: 5965-5970.

167. Gajewski TF, Woo SR, Zha Y, Spaapen R, Zheng Y, et al. (2013) Cancer immunotherapy strategies based on overcoming barriers within the tumor microenvironment. Current opinion in immunology 25: 268-276.

168. Gao P, Ding Q, Wu Z, Jiang H, Fang Z (2010) Therapeutic potential of human mesenchymal stem cells producing IL-12 in a mouse xenograft model of renal cell carcinoma. Cancer Lett 290: 157-166.

169. Seo SH, Kim KS, Park SH, Suh YS, Kim SJ, et al. (2011) The effects of mesenchymal stem cells injected via different routes on modified IL-12mediated antitumor activity. Gene therapy 18: 488-495.

170. Ryu CH, Park SH, Park SA, Kim SM, Lim JY, et al. (2011) Gene therapy of intracranial glioma using interleukin 12-secreting human umbilical cord blood-derived mesenchymal stem cells. Human gene therapy 22: 733-743.

171. Hong X, Miller C, Savant-Bhonsale S, Kakanis SN (2009) Antitumor treatment using interleukin- 12-secreting marrow stromal cells in an invasive glioma model. Neurosurgery 64: 1139-1147.

172. Xu G, Jiang XD, Xu Y, Zhang J, Huang FH, et al. (2009) Adenoviralmediated interleukin-18 expression in mesenchymal stem cells effectively suppresses the growth of glioma in rats. Cell biology international 33: 466-474.

173. Kosaka H, Ichikawa T, Kurozumi K, Kambara H, Inoue S, et al. (2012) Therapeutic effect of suicide gene-transferred mesenchymal stem cells in a rat model of glioma. Cancer gene therapy 19: 572-578.

174. Zhao Y, Lam DH, Yang J, Lin J, Tham CK, et al. (2012) Targeted suicide gene therapy for glioma using human embryonic stem cell-derived neural stem cells genetically modified by baculoviral vectors. Gene therapy 19 : 189-200.

175. Aboody KS, Najbauer J, Metz MZ, D’Apuzzo M, Gutova M, et al. (2013) Neural stem cell-mediated enzyme/prodrug therapy for glioma: preclinical studies. Science translational medicine 5: 184ra59.

176. Altaner C, Altanerova V, Cihova M, Ondicova K, Rychly B, et al. (2014) Complete regression of glioblastoma by mesenchymal stem cells mediated prodrug gene therapy simulating clinical therapeutic scenario. International Journal of Cancer 134: 1458-65.

177. Kim SK, Kim SU, Park IH, Bang JH, Aboody KS, et al. (2006) Human neural stem cells target experimental intracranial medulloblastoma and deliver a therapeutic gene leading to tumor regression. Clinical Cancer Research 12: 5550-5556.

178. Martinez-Quintanilla J, Bhere D, Heidari P, He D, Mahmood U, et al. (2013) Therapeutic efficacy and fate of bimodal engineered stem cells in malignant brain tumors. Stem Cells 31: 1706-1714.

179. Ryu CH, Park KY, Kim SM, Jeong CH, Woo JS, et al. (2012) Valproic acid enhances anti-tumor effect of mesenchymal stem cell mediated HSV-TK gene therapy in intracranial glioma. Biochemical and biophysical research communications 421: 585-590.

180. Lee WY, Zhang T, Lau CP, Wang CC, Chan KM, et al. (2013) Immortalized human fetal bone marrow-derived mesenchymal stromal cell expressing suicide gene for anti-tumor therapy in vitro and in vivo. Cytotherapy 15: 1484-1497.
181. Kim KY, Kim SU, Leung PC, Jeung EB, Choi KC (2010) Influence of the prodrugs 5 -fluorocytosine and CPT-11 on ovarian cancer cells using genetically engineered stem cells: tumor-tropic potential and inhibition of ovarian cancer cell growth. Cancer Sci 101: 955-962.

182. Hong SH, Lee HJ, An J, Lim I, Borlongan C, et al. (2013) Human neural stem cells expressing carboxyl esterase target and inhibit tumor growth of lung cancer brain metastases. Cancer gene therapy 20: 678-682.

183. Gutova M, Shackleford GM, Khankaldyyan V, Herrmann KA, Shi XH, et al. (2013) Neural stem cell-mediated CE/CPT-11 enzyme/prodrug therapy in transgenic mouse model of intracerebellar medulloblastoma. Gene therapy 20: 143-150.

184. Bertrand N, Wu J, Xu X, Kamaly N, Farokhzad OC (2014) Cancer nanotechnology: the impact of passive and active targeting in the era of modern cancer biology. Adv Drug Deliv Rev 66: 2-25.

185. Roger M, Clavreul A, Venier-Julienne MC, Passirani C, Sindji L, et al. (2010) Mesenchymal stem cells as cellular vehicles for delivery of nanoparticles to brain tumors. Biomaterials 31: 8393-8401.

186. Auffinger B, Morshed R, Tobias A, Cheng Y, Ahmed AU, et al. (2013) Drug-loaded nanoparticle systems and adult stem cells: a potential marriage for the treatment of malignant glioma. Oncotarget 4: 378-396.

187. Li L, Guan Y, Liu H, Hao N, Liu T, et al. (2011) Silica nanorattledoxorubicin-anchored mesenchymal stem cells for tumor-tropic therapy. ACS nano 5: 7462-7470.

188. Duchi S, Sotgiu G, Lucarelli E, Ballestri M, Dozza B, et al. (2013) Mesenchymal stem cells as delivery vehicle of porphyrin loaded nanoparticles: effective photoinduced in vitro killing of osteosarcoma. Journal of Controlled Release 168: 225-237.

189. Schnarr K, Mooney R, Weng Y, Zhao D, Garcia E, et al. (2013) Gold Nanoparticle-Loaded Neural Stem Cells for Photothermal Ablation of Cancer. Advanced healthcare materials 2: 976-982.

190. Rachakatla RS, Balivada S, Seo GM, Myers CB, Wang H, et al. (2010) Attenuation of mouse melanoma by A/C magnetic field after delivery of bi-magnetic nanoparticles by neural progenitor cells. ACS nano 4: 7093-7104.

191. Kim J, Hall RR, Lesniak MS, Ahmed AU (2015) Stem cell-based cell carrier for targeted oncolytic virotherapy: translational opportunity and open questions. Viruses 7: 6200-6217.

192. Russell SJ, Peng KW, Bell JC (2012) Oncolytic virotherapy. Nat Biotechnol 30: 658-670.

193. Willmon C, Harrington K, Kottke T, Prestwich R, Melcher A, et al. (2009) Cell carriers for oncolytic viruses: Fed ex for cancer therapy. Mol. Ther. J. Am. Soc. Gene Ther 17: 1667-1676.

194. Dock G (1904) The influence of complicating disease upon leukemia. Am J Med Sci 127: 561-592.

195. Sze DY, Reid TR, Rose SC (2013) Oncolytic virotherapy. J Vasc Interv Radiol 24: 1115-1122.

196. Ankrum JA, Miranda OR, Ng KS, Sarkar D, Xu C, et al. (2014) Engineering cells with intracellular agent-loaded microparticles to control cell phenotype. Nature protocols 9: 233-245.

197. Sarkar D, Ankrum JA, Teo GS, Carman CV, Karp JM (2011) Cellular and extracellular programming of cell fate through engineered intracrine-, paracrine-, and endocrine-like mechanisms. Biomaterials 32: 3053-3061.

198. Honeth G, Staflin K, Kalliomaki S, Lindvall M, Kjellman C (2006) Chemokine-directed migration of tumor-inhibitory neural progenitor cells towards an intracranially growing glioma. Exp. Cell Res 312: 1265-1276.

199. Kim DS, Kim JH, Kwon Lee J, Choi SJ, Kim JS, et al. (2009) Overexpression of CXC chemokine receptors is required for the superior glioma-tracking property of umbilical cord blood-derived mesenchymal stem cells. Stem cells and development 18: 511-20.

200. Zielske SP, Livant DL, Lawrence TS (2009) Radiation increases invasion of gene-modified mesenchymal stem cells into tumors. Int J Radiat Oncol Biol Phys 75: 843-853.

201. Klopp AH, Spaeth EL, Dembinski JL, Woodward WA, Munshi A, et al. (2007) Tumor irradiation increases the recruitment of circulating 
Citation: Malik A, Rasool R, Khan SR, Waquar S, lqbal J, et al. (2017) Development of Anti-Cancer Stem Cells as Theranostic Agents in the Treatment of Different Cancer Types: An Update. J Carcinog Mutagen 8: 291. doi:10.4172/2157-2518.1000291

Page 15 of 15

mesenchymal stem cells into the tumor microenvironment. Cancer research 67: 11687-11695.

202. Meacham CE, Morrison SJ (2013) Tumour heterogeneity and cancer cell plasticity. Nature 501: 328-337.

203. Hanahan D (2014) Rethinking the war on cancer. Lancet 383: 558-563.

204. Yi BR, Hwang KA, Aboody KS, Jeung EB, Kim SU, et al. (2014) Selective antitumor effect of neural stem cells expressing cytosine deaminase and interferon-beta against ductal breast cancer cells in cellular and xenograft models. Stem cell research 12: 36-48.

205. Yan C, Li S, Li Z, Peng H, Yuan X, et al. (2012) Human umbilical cord mesenchymal stem cells as vehicles of CD20-specific TRAIL fusion protein delivery: a double-target therapy against non-Hodgkin's lymphoma. Molecular pharmaceutics 10: 142-151.

206. Du W, Uslar L, Sevala S, Shah K (2014) Targeting c-Met receptor overcomes TRAIL-resistance in brain tumors. PLoS One 9: e95490.

207. Kim SM, Woo JS, Jeong CH, Ryu CH, Jang JD, et al. (2014) Potential Application of Temozolomide in Mesenchymal Stem Cell-Based TRAIL Gene Therapy Against Malignant Glioma. Stem cells translational medicine 3: 172-182.

208. Tobias AL, Thaci B, Auffinger B, Rincón E, Balyasnikova IV, et al. (2013) The timing of neural stem cell-based virotherapy is critical for optimal therapeutic efficacy when applied with radiation and chemotherapy for the treatment of glioblastoma. Stem cells translational medicine 2: 655-666.

209. Reitz M, Demestre M, Sedlacik J, Meissner H, Fiehler J, et al. (2012) Intranasal delivery of neural stem/progenitor cells: a noninvasive passage to target intracerebral glioma. Stem cells translational medicine 1: 866-873.

210. Balyasnikova IV, Prasol MS, Ferguson SD, Han Y, Ahmed AU, et al. (2014) Intranasal delivery of mesenchymal stem cells significantly extends survival of irradiated mice with experimental brain tumors. Molecular Therapy 22: 140-148.

211. Burdick JA, Prestwich GD (2011) Hyaluronic acid hydrogels for biomedical applications. Adv Mater 23: H41-56.

212. Hansen K, Muller FJ, Messing M, Zeigler F, Loring JF, et al. (2010) A 3dimensional extracellular matrix as a delivery system for the transplantation of glioma-targeting neural stem/progenitor cells. Neurooncology 12: 645-654.
213. Goren A, Dahan N, Goren E, Baruch L, Machluf M (2010) Encapsulated human mesenchymal stem cells: a unique hypoimmunogenic platform for long-term cellular therapy. FASEB J 24: 22-31.

214. Ríhová B (2000) Immunocompatibility and biocompatibility of cell delivery systems. Adv Drug Deliv Rev 42: 65-80.

215. Reagan MR, Seib FP, McMillin DW, Sage EK, Mitsiades CS, et al. (2012) Stem cell implants for cancer therapy: TRAIL-expressing mesenchymal stem cells target cancer cells in situ. Journal of breast cancer 15(3): 273-282.

216. Kauer TM, Figueiredo JL, Hingtgen S, Shah K (2012) Encapsulated therapeutic stem cells implanted in the tumor resection cavity induce cell death in gliomas. Nature Neurosci 15: 197-204.

217. Menon LG, Pratt J, Yang HW, Black PM, Sorensen GA, et al. (2012) Imaging of human mesenchymal stromal cells: homing to human brain tumors. Journal of neuro-oncology 107: 257-267.

218. Thu MS, Najbauer J, Kendall SE, Harutyunyan I, Sangalang N, et al. (2009) Iron labeling and pre-clinical MRI visualization of therapeutic human neural stem cells in a murine glioma model. PLoS One 4: e7218.

219. Chien LY, Hsiao JK, Hsu SC, Yao M, Lu CW, et al. (2011) In vivo magnetic resonance imaging of cell tropsim, trafficking mechanism, and therapeutic impact of human mesenchymal stem cells in a murine glioma model. Biomaterials 32: 3275-3284.

220. Gutova M, Frank JA, D'Apuzzo M, Khankaldyyan V, Gilchrist MM, et al. (2013) Magnetic Resonance Imaging Tracking of Ferumoxytol-Labeled Human Neural Stem Cells: Studies Leading to Clinical Use. Stem cells translational medicine 2: 766-775.

221. Hasenbach K, Wiehr S, Herrmann C, Mannheim J, Cay F, et al. (2012) Monitoring the glioma tropism of bone marrow-derived progenitor cells by 2-photon laser scanning microscopy and positron emission tomography. Neuro-oncology 14: 471-481.

222. Sweeney TJ, Mailänder V, Tucker AA, Olomu AB, Zhang W, et al. (1999) Visualizing the kinetics of tumor-cell clearance in living animals. Proc Natl Acad Sci U S A 96: 12044-12049.

223. Garcia-Castro J, Alemany R, Cascallo M, Martinez-Quintanilla J, del Mar Arriero M, et al. (2010) Treatment of metastatic neuroblastoma with systemic oncolytic virotherapy delivered by autologous mesenchymal stem cells: an exploratory study. Cancer gene therapy 17: 476-483. 